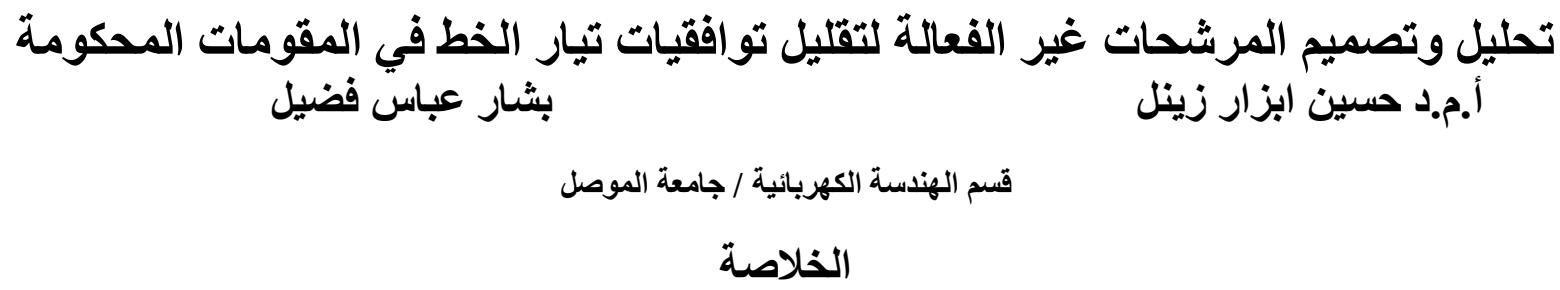

سعى العديد من الباحثين إلى استخدام طرائق مختلفة لتقليل التوافقيات الظاهرة في موجة تيار الإدخال

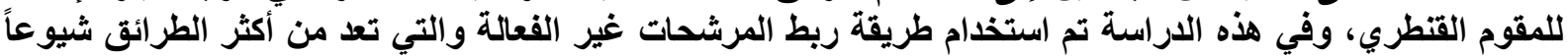

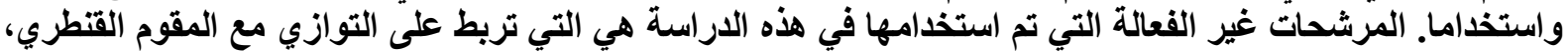

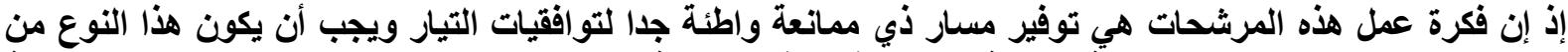

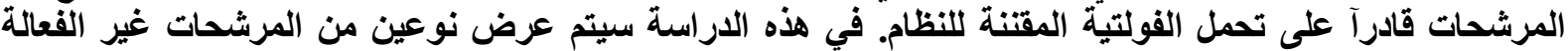

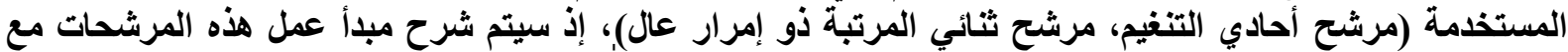

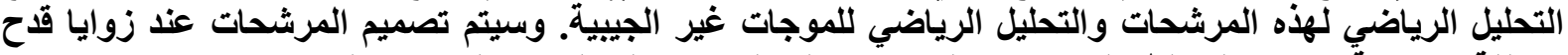
مختلفة. ودراسة الإجهاد المسلط على عناصر المرشح وعلى المرشح بالكامل عند كل حالات التصميم.

\title{
Analysis and Design of Passive Filters to Reduce Line Current Harmonics for Controlled Rectifiers
}

\author{
Hussein I.Zynal
}

Ph. D.

\section{Bashar A.Fadeel}

M.Sc.

Dept. of Electrical Engineering, Mosul University

\begin{abstract}
Many researchers have sought to use different methods to reduce harmonics in the input current wave of the rectifier, In this study the method of passive filter connections are used, which is the most commonly used method. The filters that have been used in this study are connected in parallel (shunt) with the rectifier. Where the idea of these filters to provide a path with a very low impedance to the harmonics of the current. These filters must be capable of withstanding rated voltage of the system. In this study two types of passive filters are explained and used (Single tuned filter and Second order high-pass filters). Also mathematical analysis of these types of filters and waves are given. Filters were designed at several values of the firing angles of the rectifier.

Keywordes: Harmonics, Passive filters, Controlled rectifiers.
\end{abstract}


قائمة الرموز والمختصرات

\begin{tabular}{|c|c|c|}
\hline 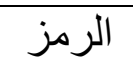 & الوحدة & الوصف \\
\hline$E$ & $\mathrm{~V}$ & جذر متوسط التربيع للفولتية \\
\hline$I$ & A & جذر متوسط التربيع للتبار \\
\hline$S$ & VA & القدرة الظاهرية \\
\hline$P$ & W & معدل سريان القدرة \\
\hline$G$ & VAr & القدرة غير الفعالة \\
\hline$n$ & ----- & مرتبة التو افقية \\
\hline$L$ & $\mathrm{H}$ & محاثة المرشح \\
\hline$R$ & $\Omega$ & مقاومة المرشح \\
\hline Stress & ----- & الإجهاد الكلي \\
\hline Stress & ----- & إجهاد الفولتية \\
\hline Stress & ----- & إجهاد التيار \\
\hline
\end{tabular}

\begin{tabular}{|c|c|c|}
\hline الرمز & الوحدة & الوصف \\
\hline$T H D$ & $\%$ & التشوه التو افقي الكلي \\
\hline$P_{\text {in (real })}$ & $\mathrm{W}$ & القدرة الحقيقية من جهة الإدخال \\
\hline$P_{\text {in (app.) }}$ & VA & القدرة الظاهرية من جهة الإدخال \\
\hline$I_{1(r m s)}$ & A & الأسباسية المؤثرة لتيار المركبة \\
\hline$I_{T(r m s)}$ & A & القيمة المؤثرة للتيار \\
\hline$v_{a}$ & $\mathrm{~V}$ & الققيمة الآنية لفولتية إدخال \\
\hline$i_{a}$ & A & القيمة الآنية لتيار إدخال المقوم \\
\hline$I_{\mathrm{a}}$ & A & معدل تبار الحمل \\
\hline$Z f(s)$ & $\Omega$ & ممانعة المرشح بصيغة لابلاس \\
\hline$f_{0}$ & $\mathrm{~Hz}$ & التردد ألرنيني \\
\hline$Q_{c}$ & ----- & عامل الجودة \\
\hline
\end{tabular}

إن استخدام الأجهزة التي تحتوي على عناصر وأجزاء من دوائر الكترونيات القدرة في الحياة اليومية

المقدمة:

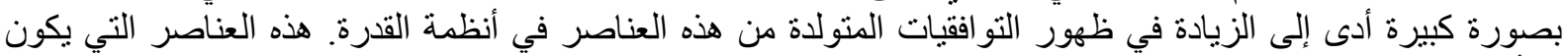

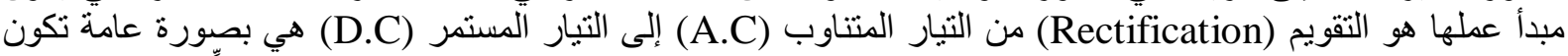

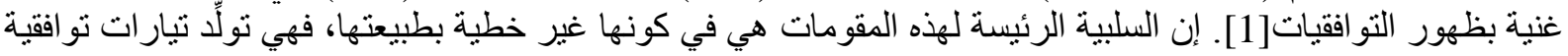

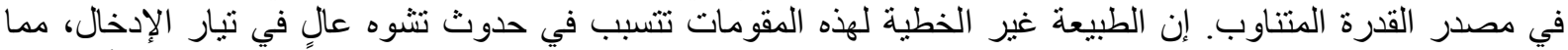

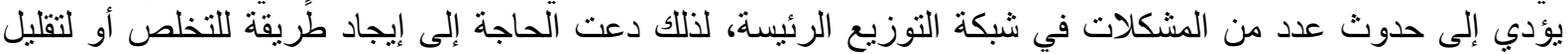

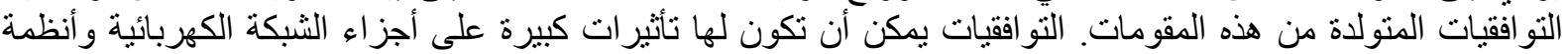

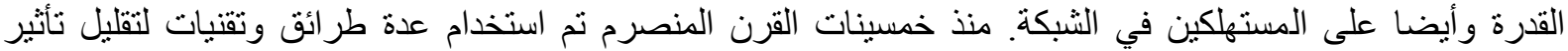

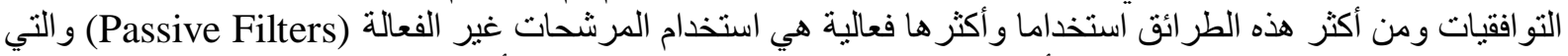

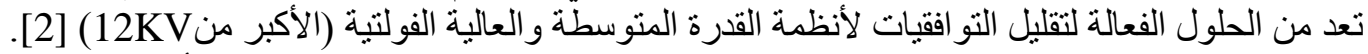

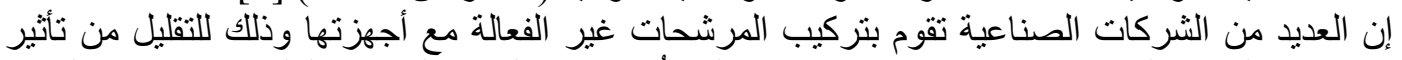

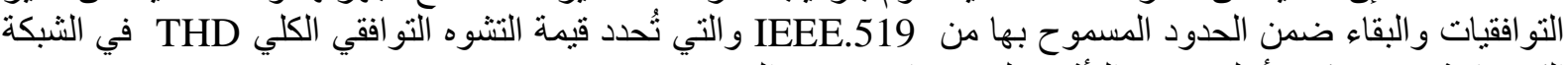
الكهربائية بـ 5\% كحد أعلى و عدم التأثير على مصدادر تجهيز القدرة [3ن].

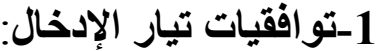

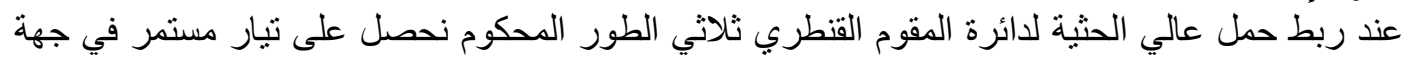

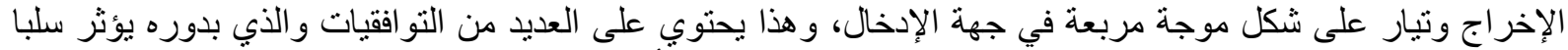

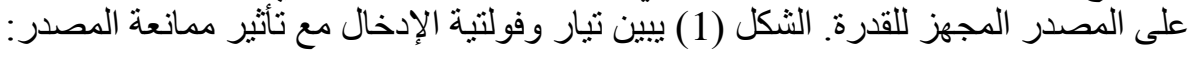

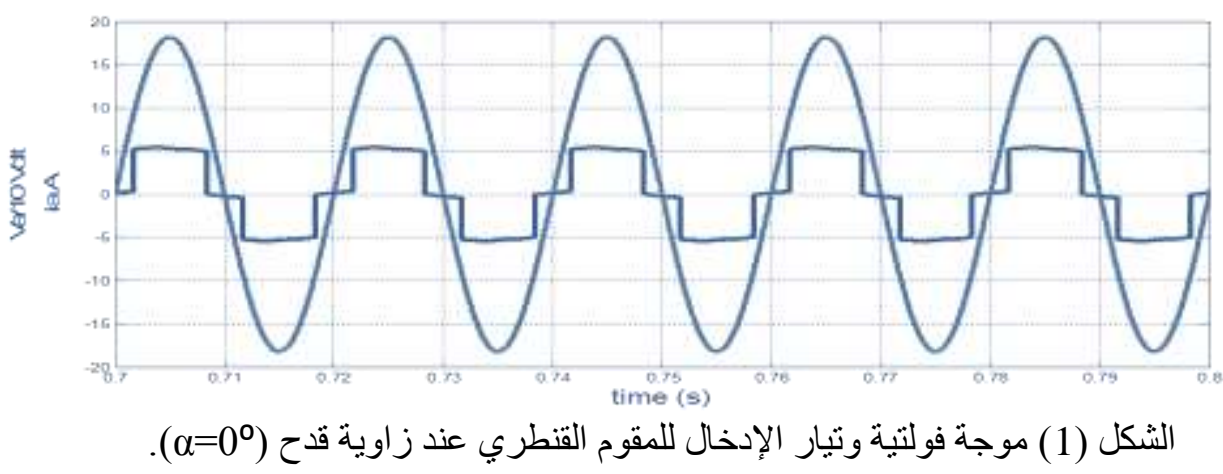


باستخدام منو الية فورير لتحليل الموجات يمكن أن نصيغ معادلة تيار الإدخال بالخطوات الآتية على افتراض

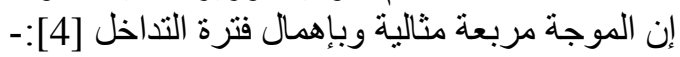

$i_{s}(t)=\sum_{n=1,5,7 \ldots}^{\infty} \sqrt{2} I_{s n} \sin \left(n \omega t+\phi_{n}\right)$ For $n=1,5,7,11,13$

$I_{s n}=\frac{1}{\sqrt{2}} \sqrt{a_{n}^{2}+b_{n}^{2}}=\frac{2 \sqrt{2} I_{a}}{n \pi} \sin \frac{n \pi}{3}$

$\phi_{n}=\tan ^{-1} \frac{a_{n}}{b_{n}}$

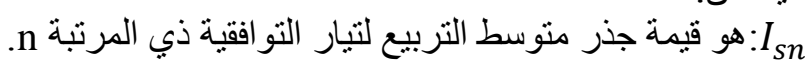

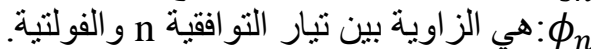

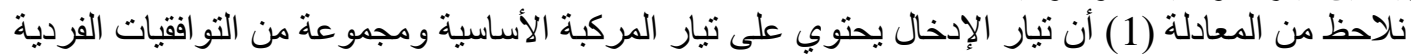

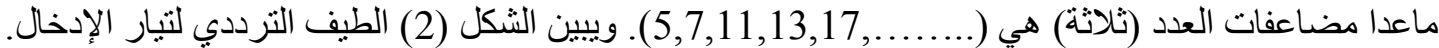

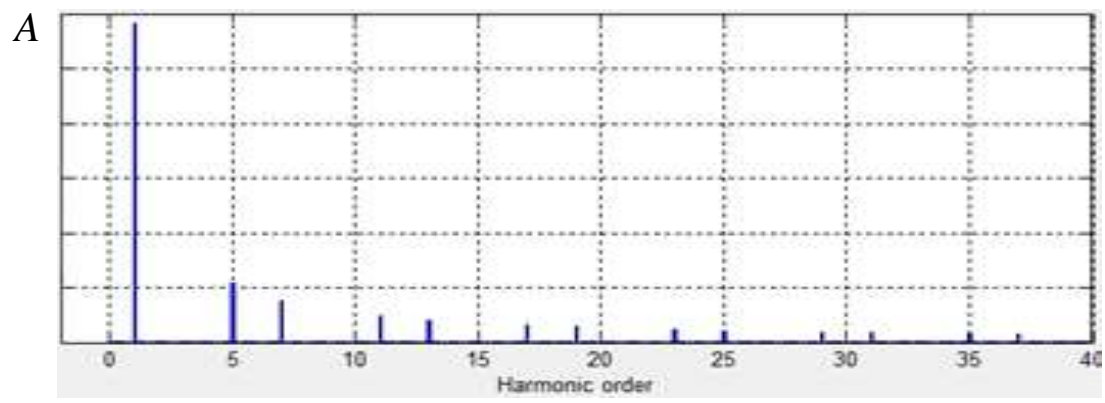

الشكل (2) الطيف الترددي لتيار الإدخال للمقوم القنطري عند م=0 ع.

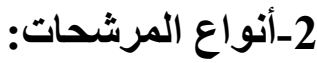

\section{أمرشتح الإمرار الحزمي (Band-Pass Filters):}

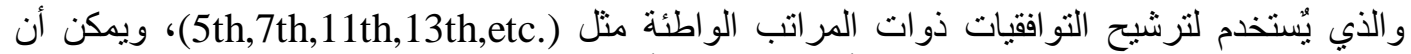
يُضبط (يُنغم) لإلغاء تردد واحد فقط ويسمى (مرشحات أحادية التنغيم) أو ترددين اثثنين ويسمى (مرشحات ثنائية التنغيم)

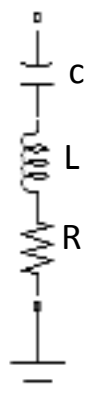

(a)

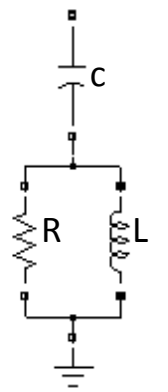

(b)

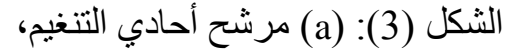

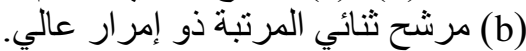

\section{ب-مرشـح الإمرار العالي (High-Pass Filters):}

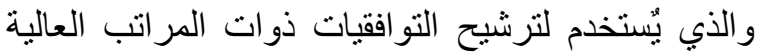

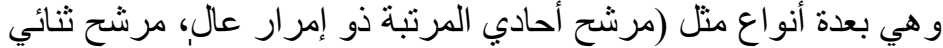

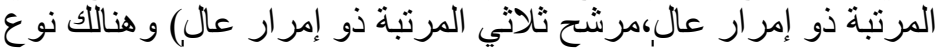

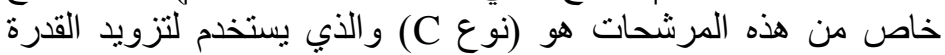

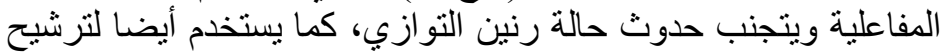

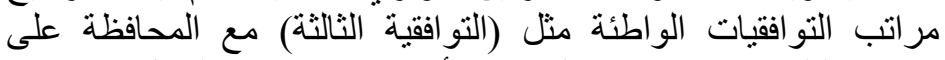

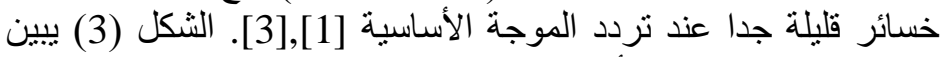

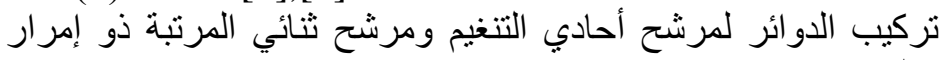
عالي. - مئب 1-2 مرشحات أحادية التنغيم: 
في هذا النوع من المرشحات تتكون الدائرة من منسعة ومحاثة ومقاومة على التو الي كما مبين في الثكل

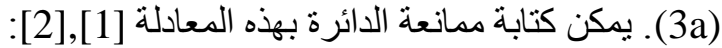

$Z(S)=R+j \omega L-\frac{j}{\omega C}=R+S L+\frac{1}{S C}=\frac{R C S+L C S^{2}+1}{S C}$

$Z f(S)=\frac{L C S^{2}+R C S+1}{C S}$

$Z f(S)=L S+R+\frac{1}{C S}$

من المعادلة (4) يمكن إيجاد التردد ألرنيني وكما يلي [6]: يؤخذ الجزء الخيالي من المعادلة (5) ويعوض عن كل S بـ م ز ينتج $j \omega_{0} L+\frac{1}{j \omega_{0} C}=0$

$\therefore f_{0}=\frac{1}{2 \pi \sqrt{L C}}$

$Q_{c}=\frac{\sqrt{\frac{L}{C}}}{R}$

إذ إن قيمة الدقاومة هي التي تحدد قيمة الحدة للمرشح وأيضا قيمة عامل الجودة Q وحسب المعادلة الآتية [3]:

ويمكن تعريف عامل الجودة:هو النسبة بين أعظم طاقة خزن إلى معدل القدرة المبددة خلال دورة وقيمته

تحدد عرض الحزمة و عمق النتشيح عند تردد الانشقاق ألرنيني.

$$
\text { 2-2 مرشح ثنائي المرتبة ذو إمر ار عالي: }
$$

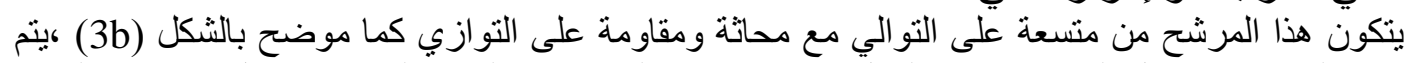

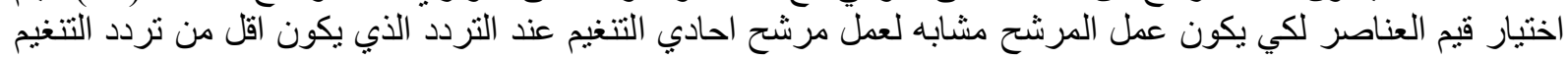
وشبيه بمرشح احادي المرتبة ذبي امرار عال, عند الترددات العالية.

عند الترددات الواطئة يتصرف المرشح وكأنما (LC) على التوالي، اما عند الترددات العالية فتكون كأما

$$
\text { (RC) }
$$

وتعد من أكثر المرشحات المستخذمة مع مرافقات مرشحات الامرار العالي المستخدمة في الأنظمة الصناعية. و عند زيادة

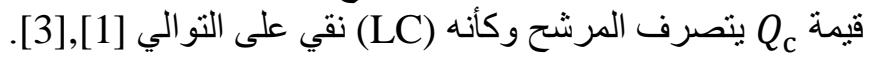

$Z f(S)=\frac{R L C S^{2}+L S+R}{S(C L S+C R)}$

يمكن كتابة معادلة الممانعة لدائرة المرشح وكما يأني [1]:

3- 3 متطلبات تصميم المرشحات:

عند تصميم المرشحات غير الفعالة هنالك ثوابت يجب معرفتها قبل عملية التصميح وهي [3]:

1 1 مقدار القدرة غير الفعالة المعوضة إلى الدائرة.

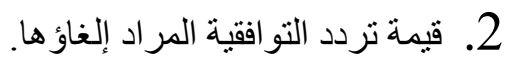

3. ع عامل الجودة والتي تحدد عرض التراد الحزمة و عمق الترشيح عند التردد المطلوب.

نلاحظ من الثكل (1) أن شكل موجة التبار غير جيبي لذلك لحساب قيمة القدرة غير الفعالة المعوضة

المطلوبة يجب أن نتعرف على العلاقات الآتية [7] [8]: 


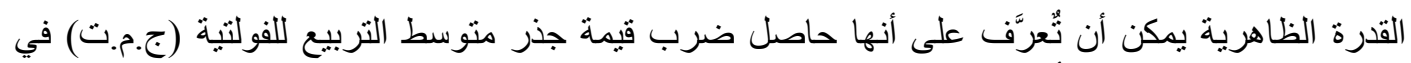

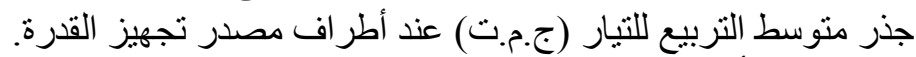

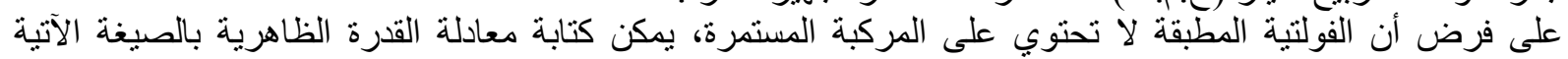

$$
S^{2}=\left(\sum_{1}^{n} E_{n}^{2}\right)\left(\sum_{1}^{n} I_{n}^{2}\right)
$$

2-3 القدرة غير الفعالة:

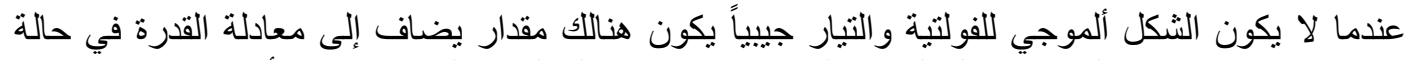

كون الأحمال غير خطية ويسمى هذا المقدار عامل التشوه، لذا يمكن كتابة معادلة القدرة الظاهرية كما يأتي [7],_[8]:

$$
S^{2}=P^{2}+Q^{2}+D^{2}
$$
تشمل القدرة المفاعلية وقدرة التشوه.

$S^{2}-P^{2}=\left(\sum_{1}^{n} E_{n}{ }^{2}\right)\left(\sum_{1}^{n} I_{n}{ }^{2}\right)-\left(\sum_{1}^{n} E_{n} I_{n} \cos \psi_{n}\right)^{2}$

$\therefore S^{2}-P^{2}=\left(\sum_{1}^{n} E_{n} I_{n} \sin \psi_{n}\right)^{2}+\sum_{m=1}^{m=n} \sum_{1}^{n}\left[E_{n}{ }^{2} I_{m}{ }^{2}-E_{n} E_{m} I_{n} I_{m} \cos \left(\psi_{n}-\psi_{m}\right)\right]$

$\therefore S^{2}-P^{2}=\left(\begin{array}{c}\text { agroup of terms } \\ \text { ivolving like } \\ \text { freq. products }\end{array}\right)+\left(\begin{array}{c}\text { agroup of terms } \\ \text { involving cross }- \\ \text { freq.products }\end{array}\right)$.

أما إذا كانت مراتب التو افقيات الموجودة في موجة الفولتية هي مراتب التو افقيات نفسها لموجة التيار و الحمل

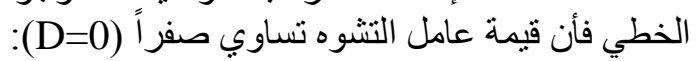

$S^{2}=P^{2}+Q^{2}$

$G^{2}=\left(Q^{2}+D^{2}\right)=S^{2}-P^{2}$

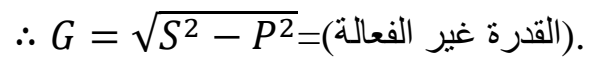

حيث إن G: هي مقدار القدرة غير الفعالة وتحتوي على تأثثر كل من القدرة المفاعلية وتأثثر التشوه.

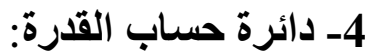

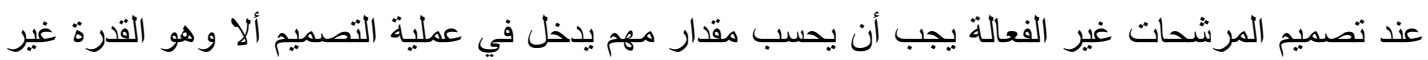

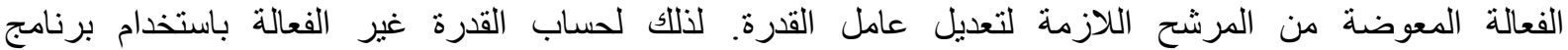

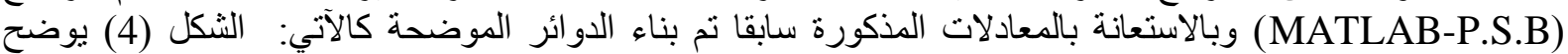

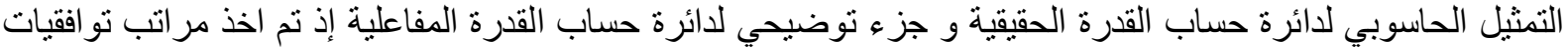

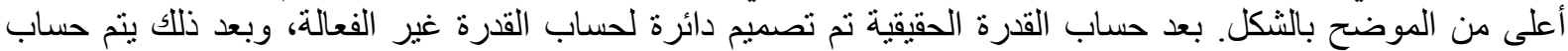
عامل القدرة وذلك بقسمة قيمة القدرة الحقيقية على قيمة القدرة الظاهرية. الثكل (5) يوضئة يوضح التمثيل الحاسوبي لدائرة حساب القدرة غير الفعالة و عامل القدرة. 

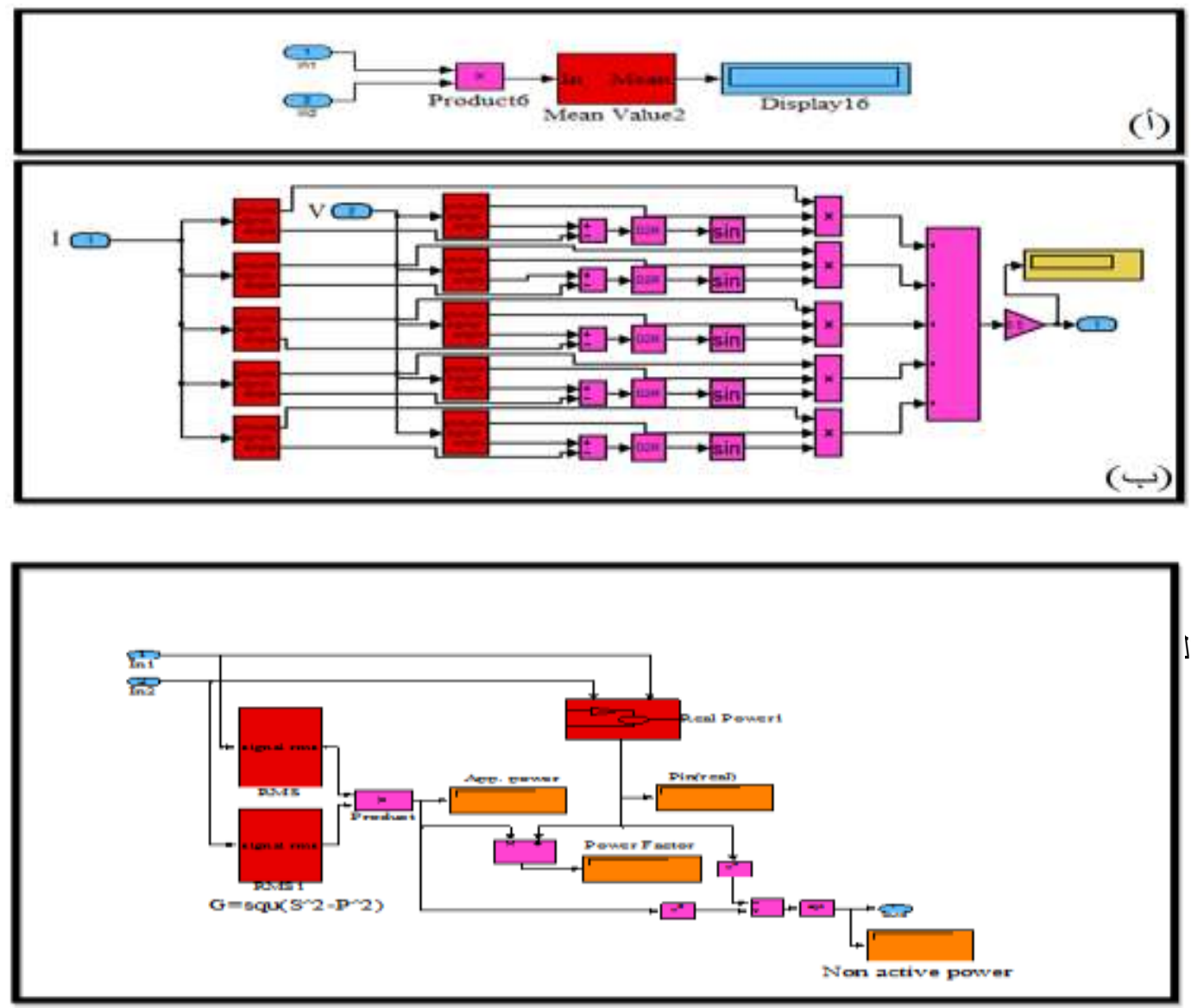

الثكل (5) يوضح التمثيل الحاسوبي لدائرة حساب القدرة غير الفعالة وعامل القدرة.

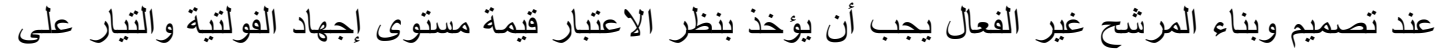

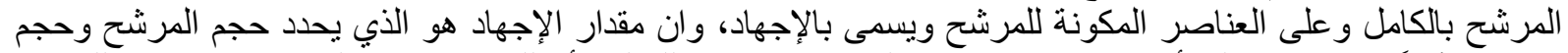

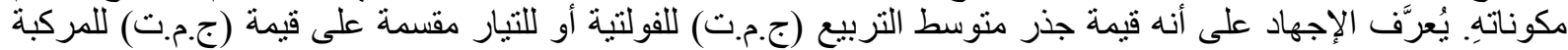

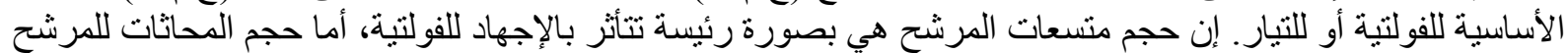
فهي تتأثر بالإجهاد للتيار [3].

Stress $=\frac{\text { Stress } V+\text { Stress } I}{2}$ الإجهاد الكلي للمرشح يُعرف بالمعادلة (28):

Stress $V=\frac{V_{r . m . s}}{V_{1 \text { r.m.s }}}$ إذ إن:

Stress $I=\frac{I_{r . m . s}}{I_{1 r . m . s}}$

في حالة وجود أكثر من منسعة في المرشح فإنه يؤخذ معدل إجهاد الفولتية لكل المنسعات.

6-خصائص الممانعة_التردد:

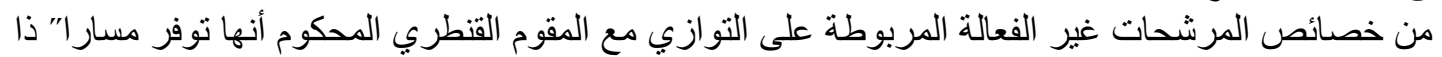

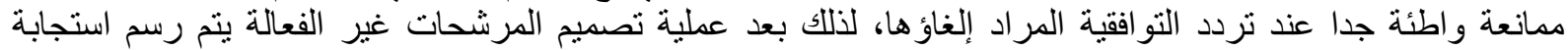


الممانعة_التردد (Impedance-Frequency Response) وذللك بتسليط مدى و اسع من الترددات لكل مرشح على حدة

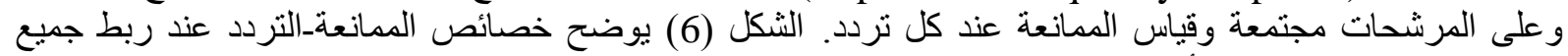

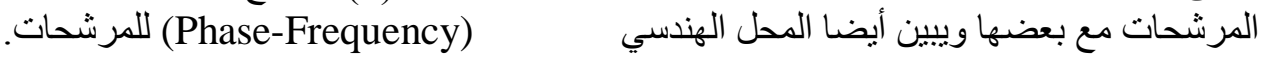
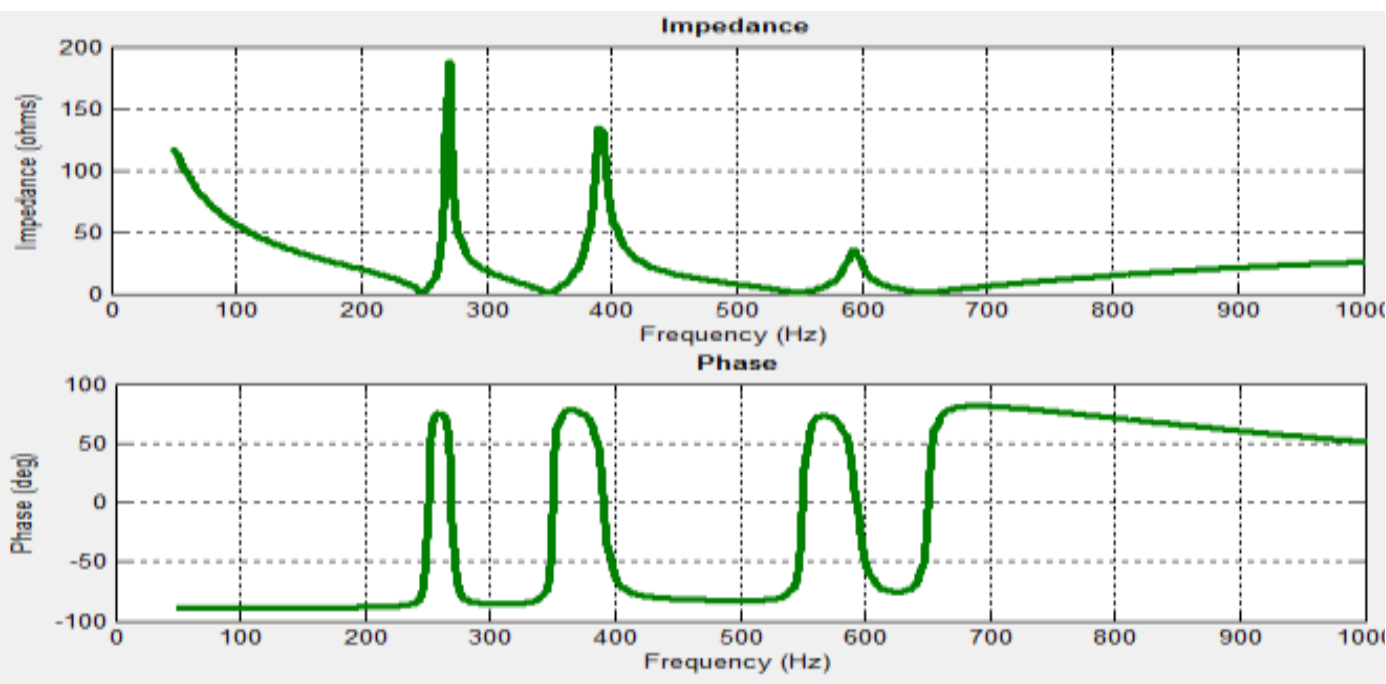

الثكل (6) يوضح خصائص الممانعة_التردد لجميع المرشحات مربوطة مع بعضها ويبين أيضا المحل الهندسي (Phase-Frequency) للمرشحات.

7-نتائج التمثيل الحاسوبي:

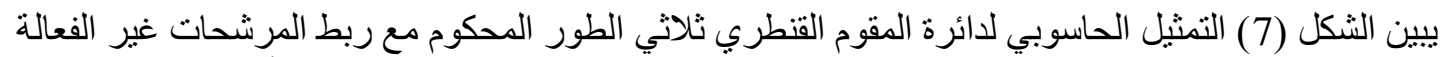

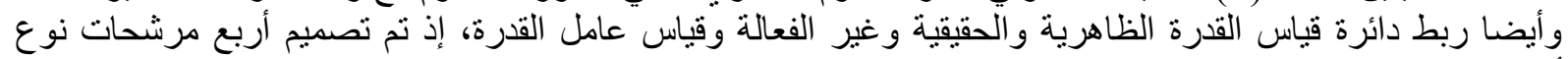

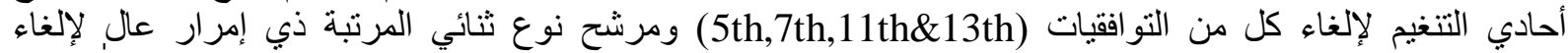
التو افقيات (م to 17th) وذلك باستخدام قيمة القدرة غير الفعالة المحسوبة لكل طور.

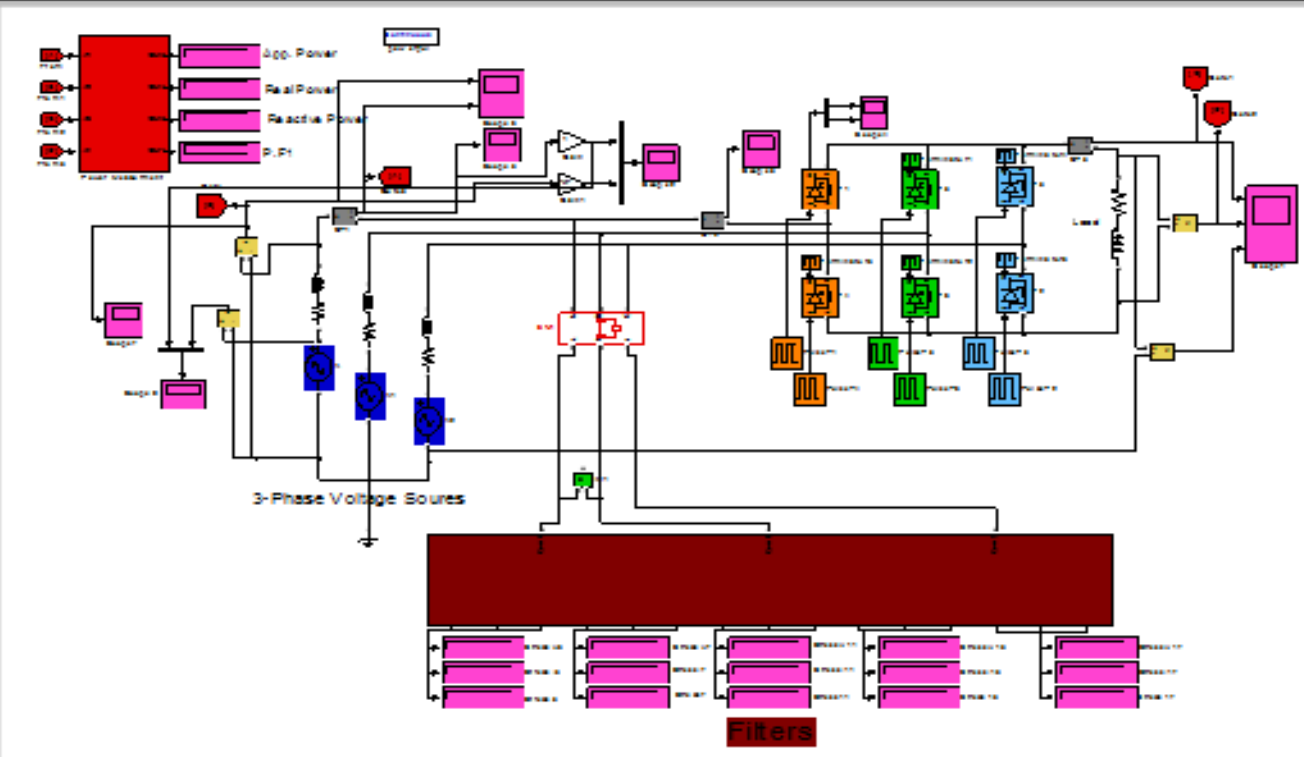

الثكل (7) التمثيل لدائرة المقوم القنطري المحكوم مع ربط المرشحات غير الفعالة 


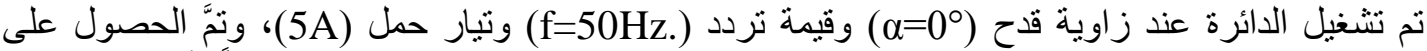

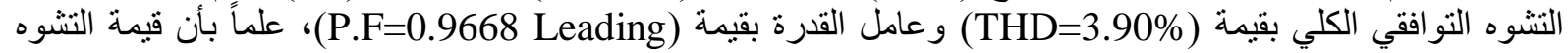

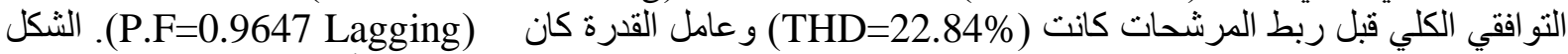

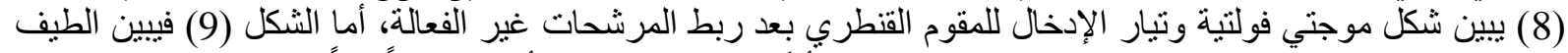

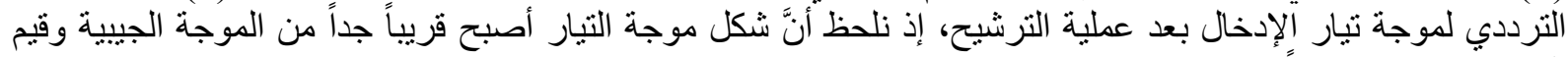

التو افقيات صغيرة جداً.

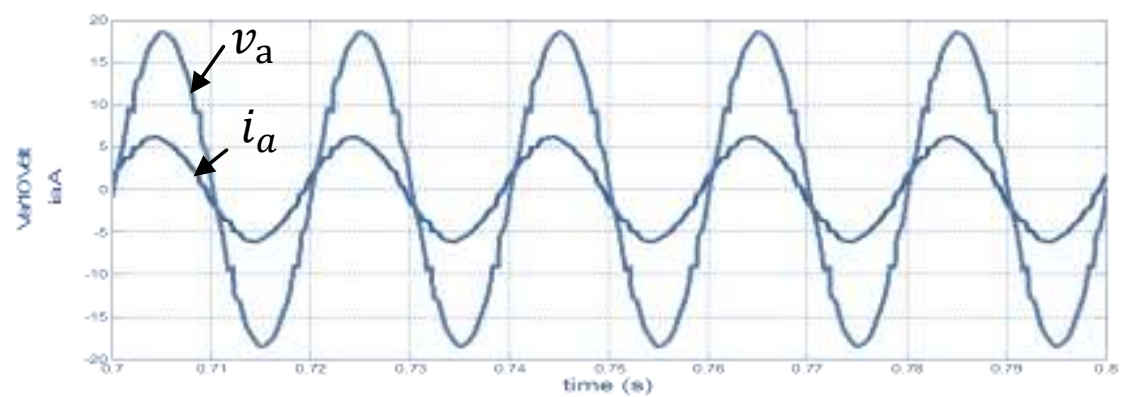

الشكل (8) موجتي فولتية وتيار الإدخال للمقوم القنطري بعد ربط المرشحات غير الفعالة

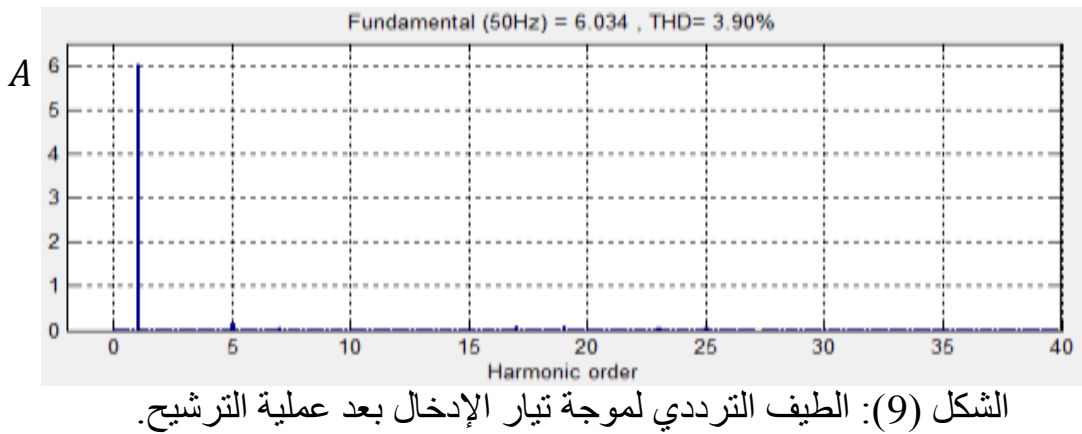

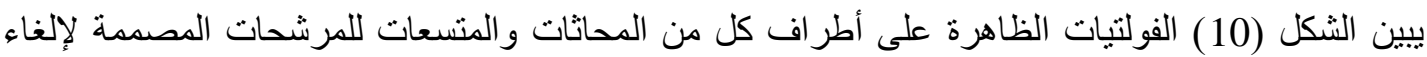

التو افقية الخامسة وتبين أيضا التو افقيات الظاهرة على المحاثات و المنسعات، إذ نلحظ من أثكال الطيف الترددي ما يأتي:

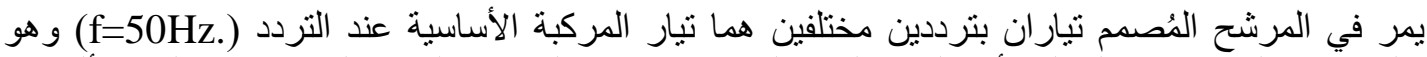

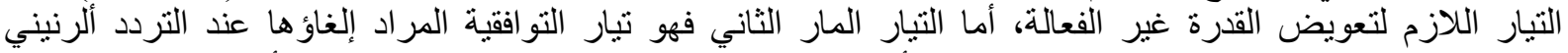

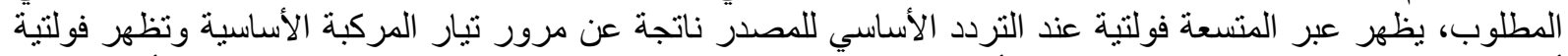

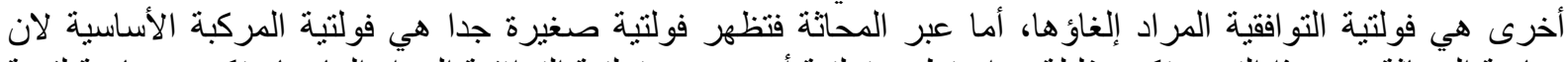

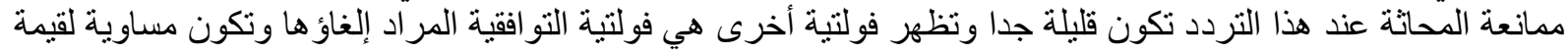
الفولتية عبر المتسعة لتلك التو افقية.

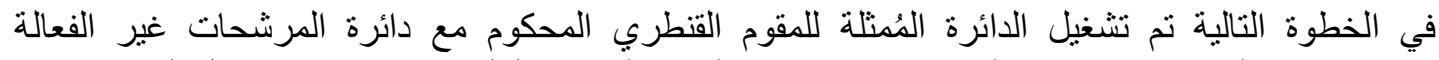

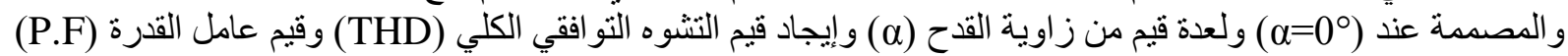

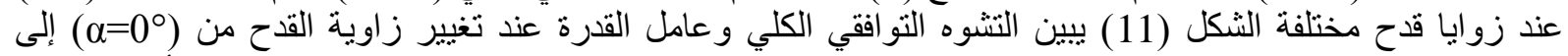

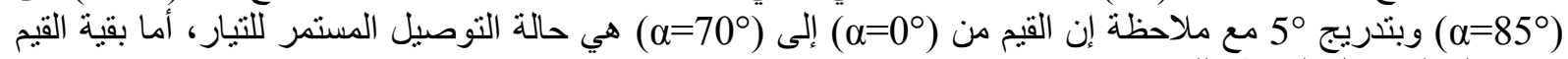
فهي حالة التوصيل المتقطع للتبار : 
زينل: تحليل وتصميم المرشحات غير الفعالة لتقليل توافقيات تيار الخط في المقومات المحكومة

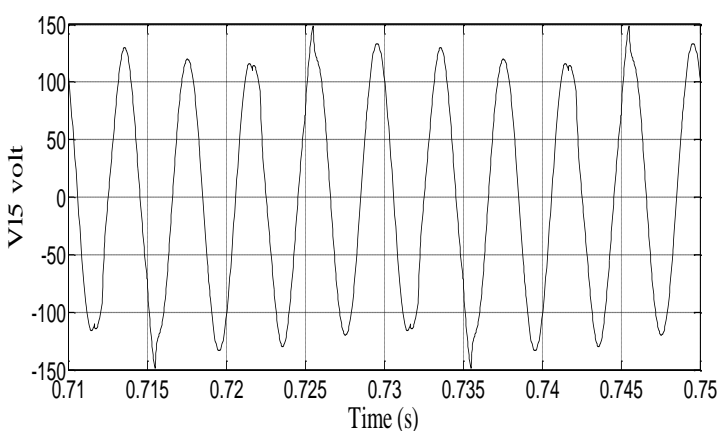

(飞)

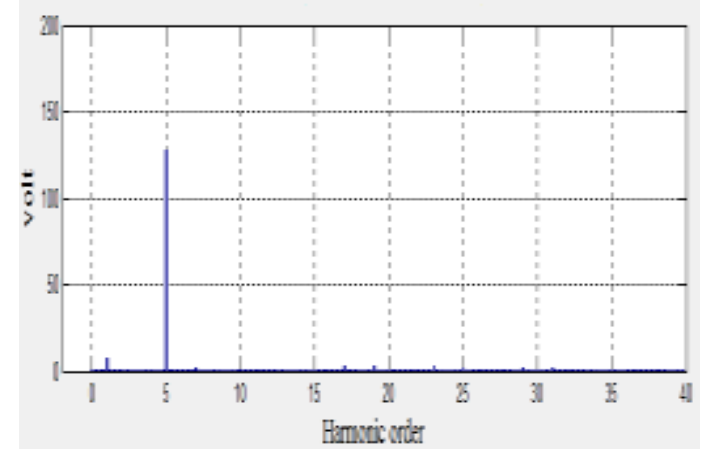

(د)

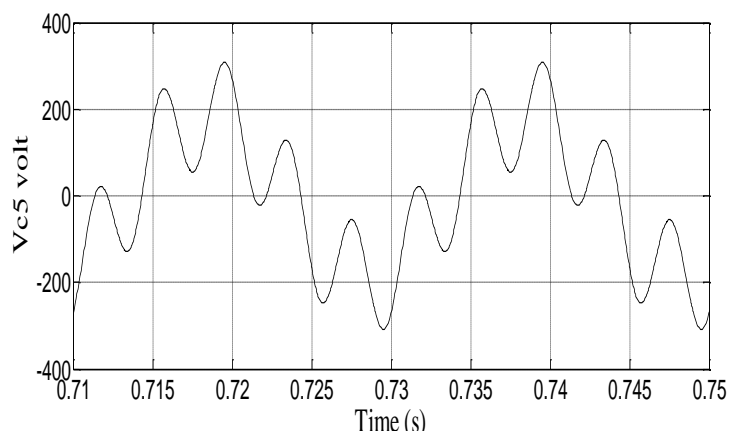

(')

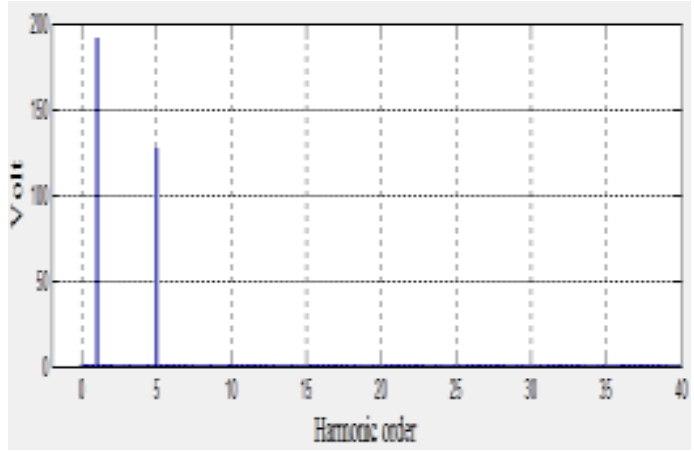

$(ب)$

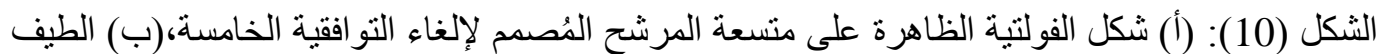

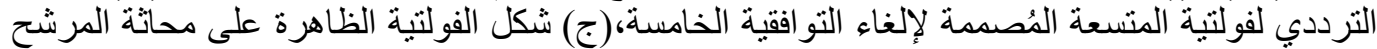

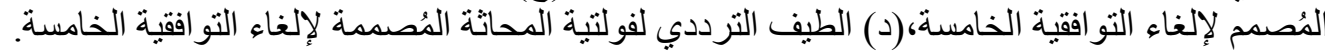

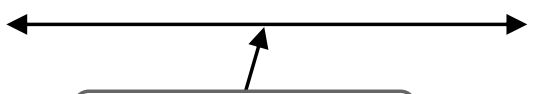

\section{Range of alpha}
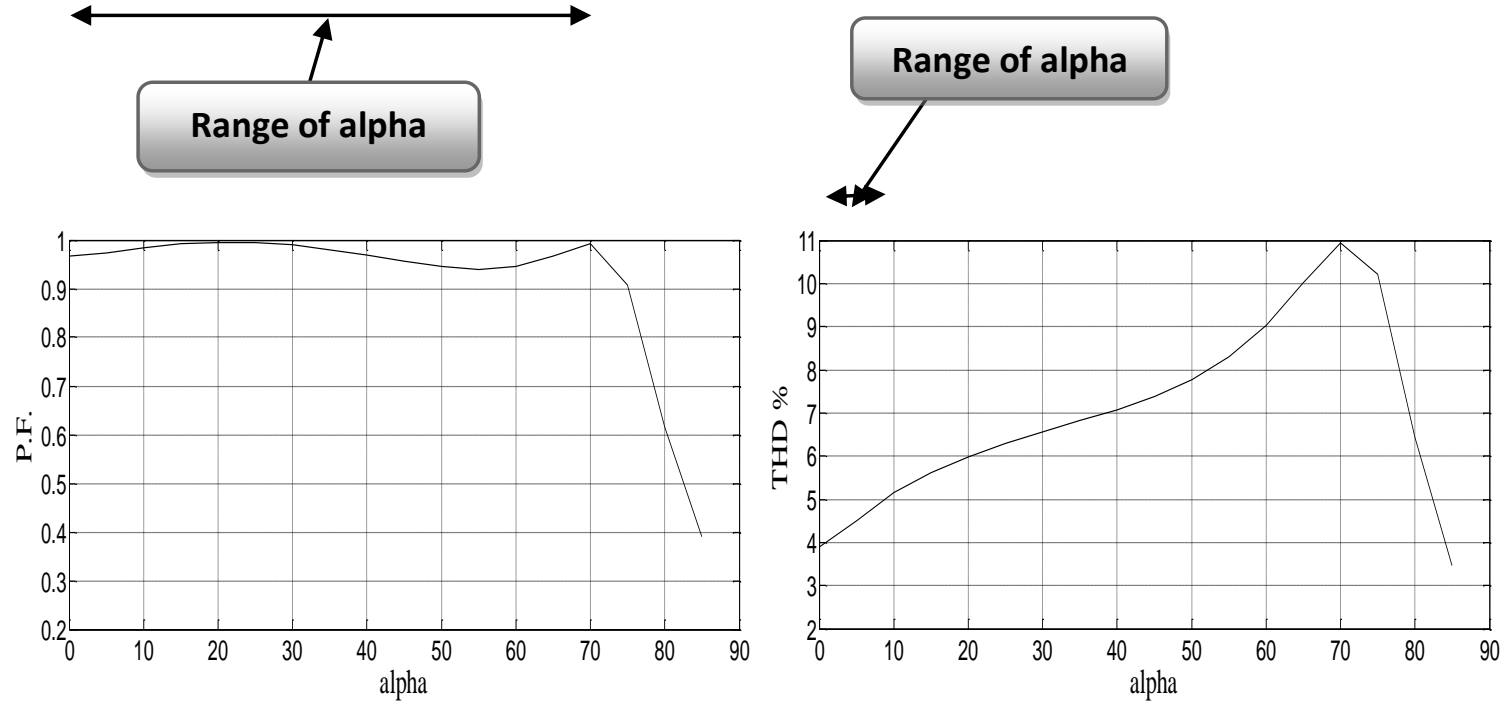

الثكل (11):(أ) العلاقة بين عامل التشوه التو افقي الكلي وزاوية القدح،

$$
\text { (ب) العلاقة بين عامل القدرة وزاوية القدح. }
$$

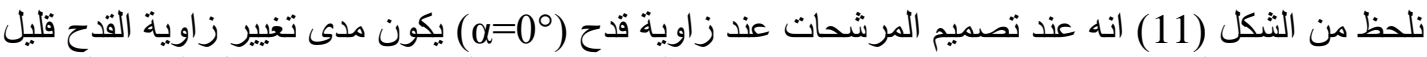

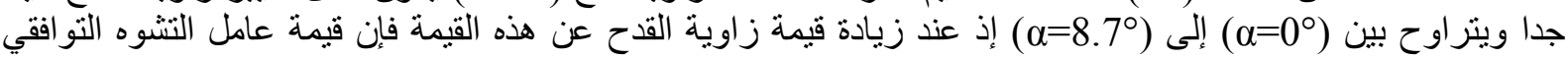




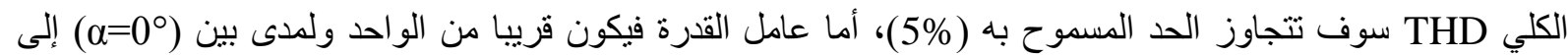
( ${ }^{\left.\circ=70^{\circ}\right) . ~ ا ل ث ك ل ~(11) ~ ي و ض ح ~ ر س م ~ ا ل ع ل ا ق ة ~ ل ك ل ~ م ن ~(ا ل ت ش و ه ~ ا ل ت و ا ف ق ي ~ ا ل ك ل ي ~ م ع ~ ز ا و ي ة ~ ا ل ق د ح) ~ و ر س م ~ ع ل ا ق ة ~(ع ا م ل ~ ا ل ق د ر ة ~}$

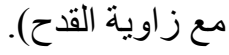

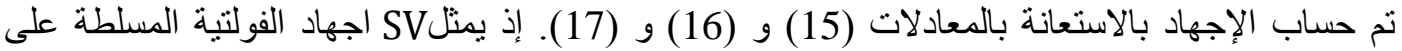
المتسعات ويمثل SI اجهاد التيار المار في المحاثات ويمثل S الإجهاد الكلي المسلط على المرشح. وكما مبين في الاشكال
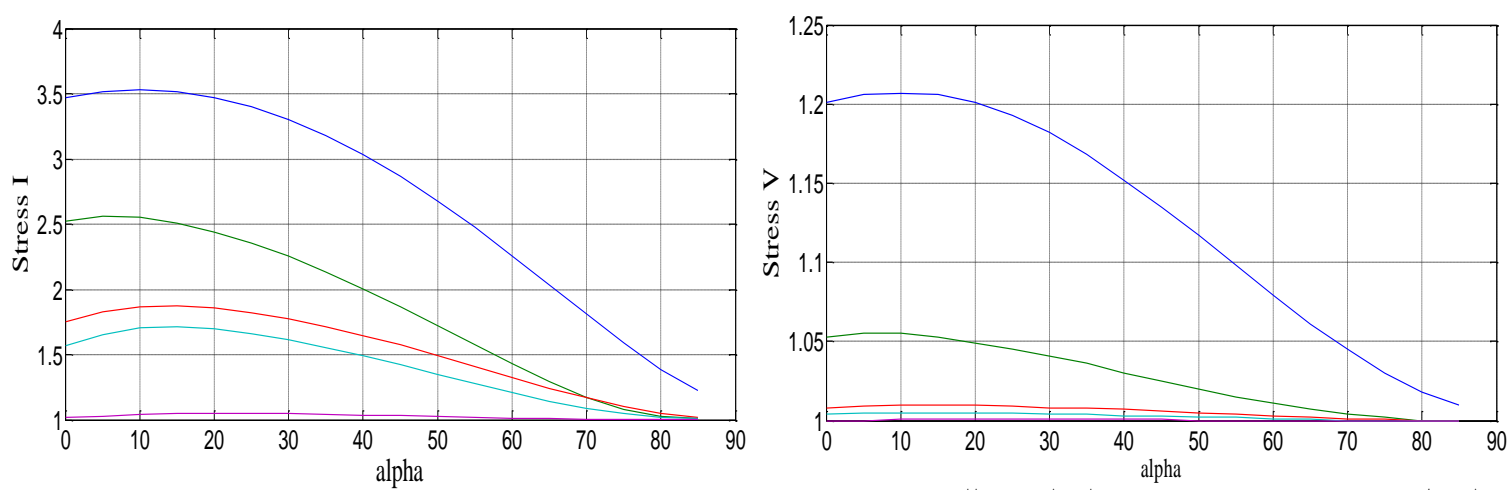
الثكل (13) قيم إجهاد التيار للمرشحات المُصممة

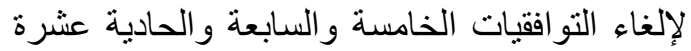
و الثالثة عشرة و السابعة عشرة مع زوايا قدح مختلفة.

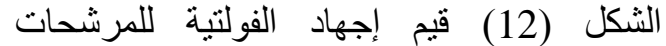

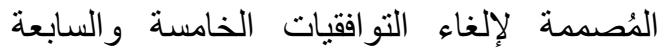

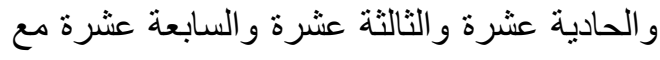
زاويا قدح مختلفة.

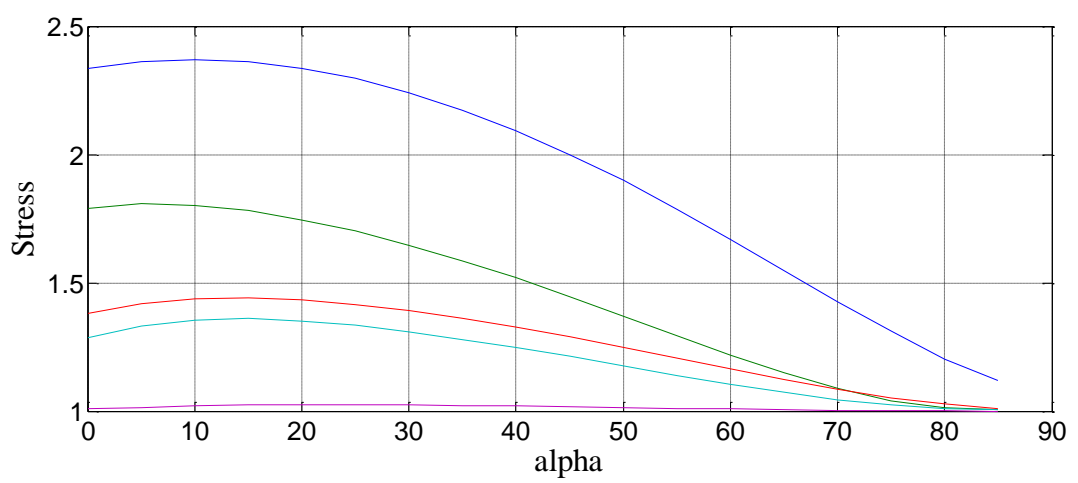

الشكل (14) قيم الإجهاد الكلي للمرشحات المُصممة لإلغاء التوافقيات الخامسة و السابعة و الحادية

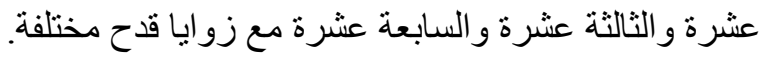

ييدو من الأشكال (12)، (13) و (14) أنَّ إجهاد الفولتية والتيار والإجهاد الكلي في تناقص مع ازدياد زاوية

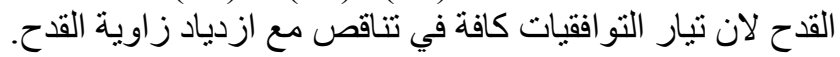

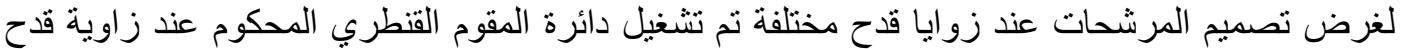

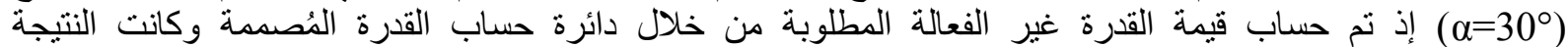

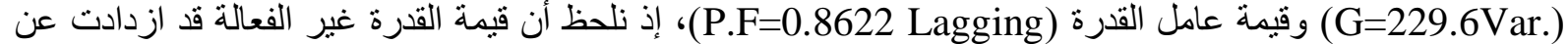

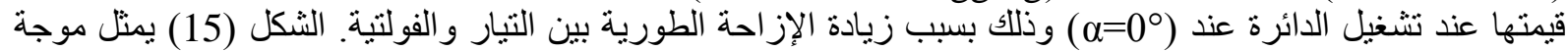

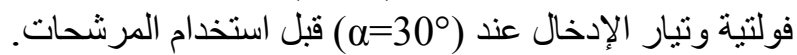




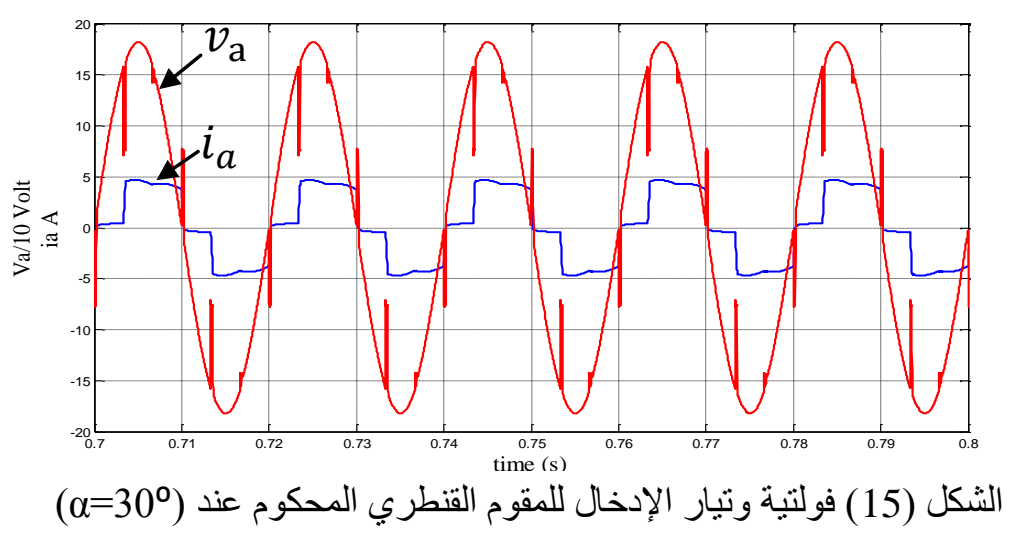

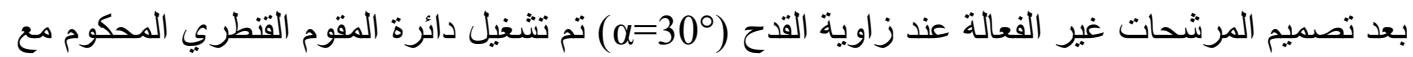

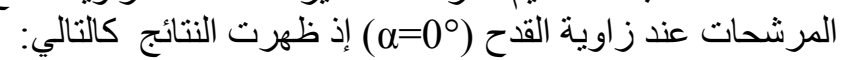

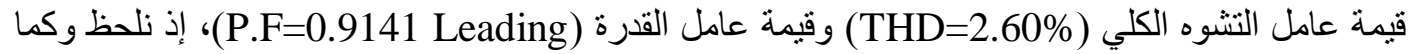

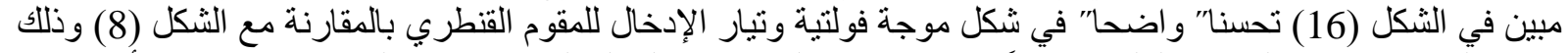

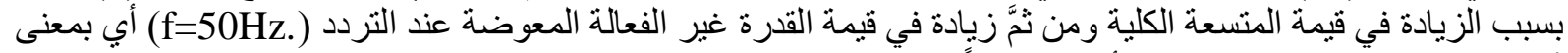

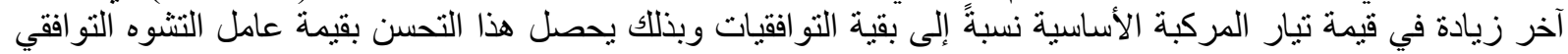
الكلي، الثكل (17) ييين الطيف الترددي لموجة تيار الإدخال للمقوم القنطري بعد عملية الترشيح. أما بالنسبة إلى عامل القدرة فإنه اقل مما في حالة التصميم عند (م=0 م) و السبب يعود إلى الزيادة في القدرة غير الفعالة المعوضة مما يجعل عامل القدرة متقدماً.

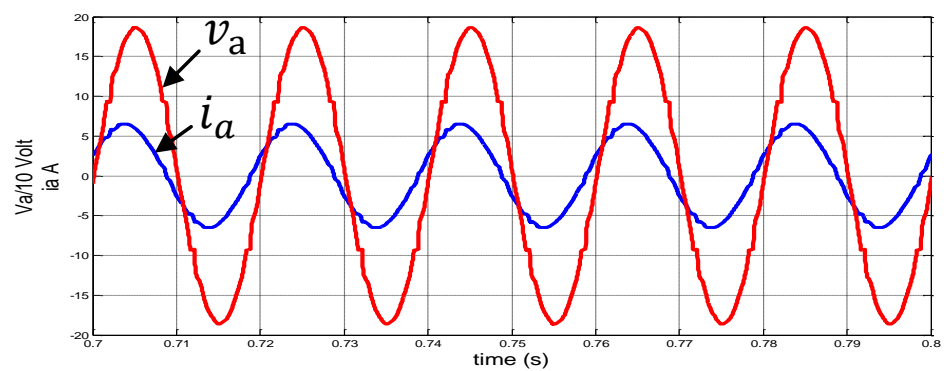

الثكل (16) موجتا فولتية وتبار الإدخال للمقوم القنطري بعد ربط المرشحات غير الفعالة المُصممة

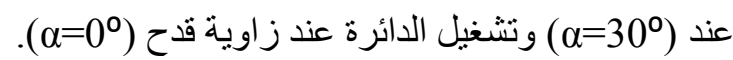

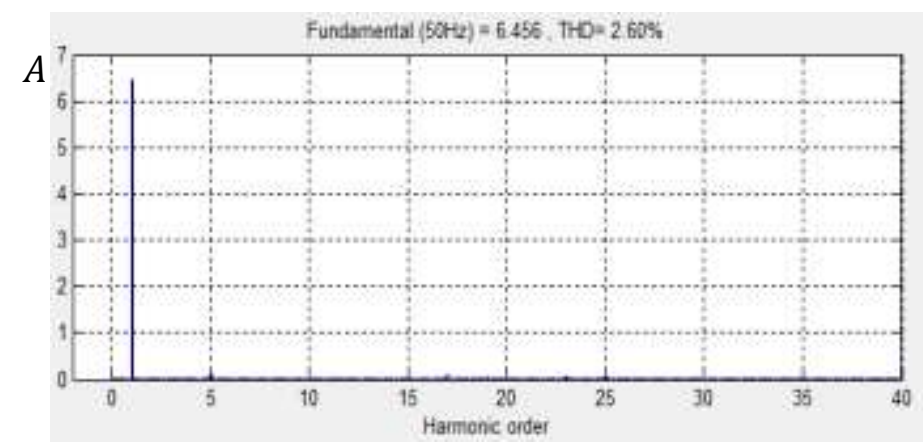

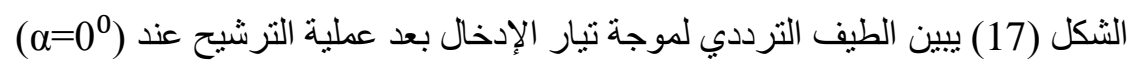




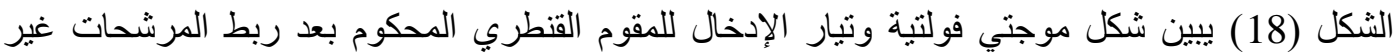

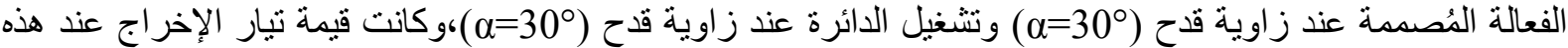

$$
\text { الزاوية (Ido }
$$

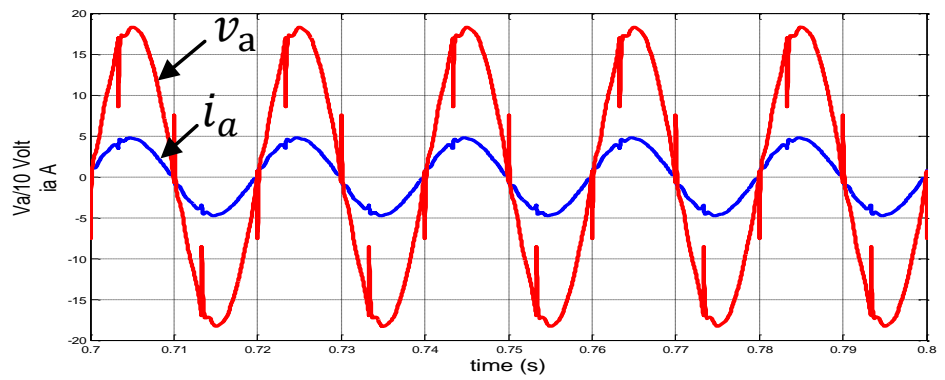

الثكل (18) موجنا فولتية وتيار الإخخال للمقوم القنطري بعد ربط المرشحات غير الفعالة

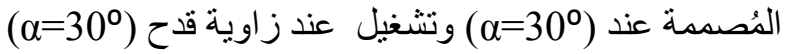

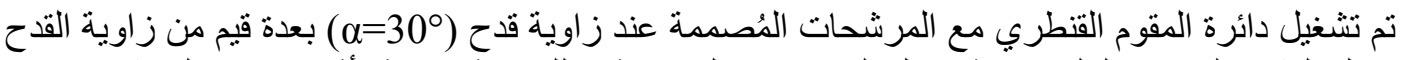

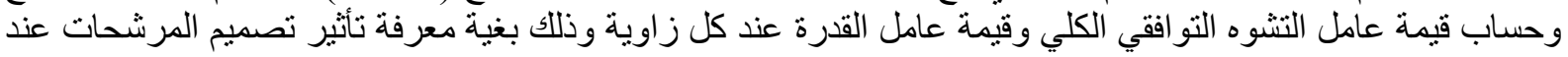

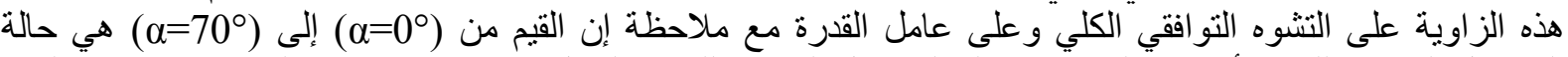

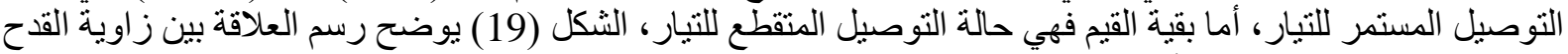

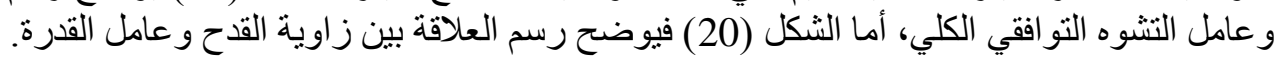

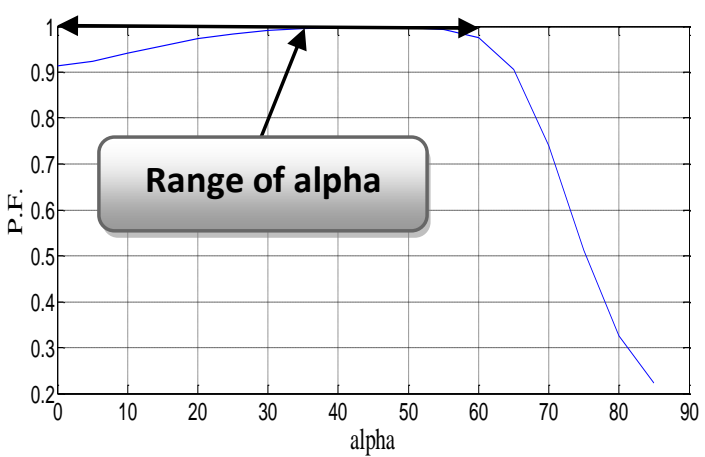

الشكل (20) رسم العلاقة بين عامل القدرة وزاوية القدح.

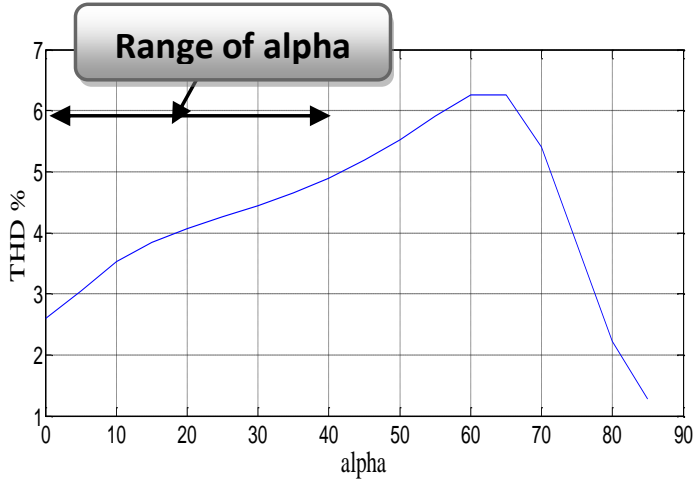

الثكل (19) رسم العلاقة بين عامل التشوه التوافقي

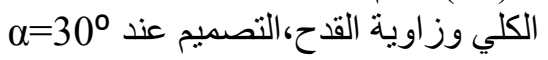

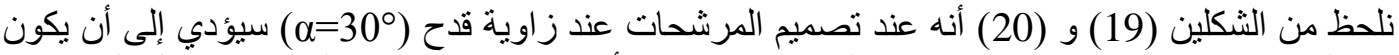

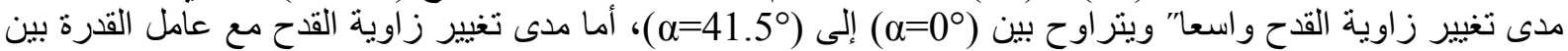
.

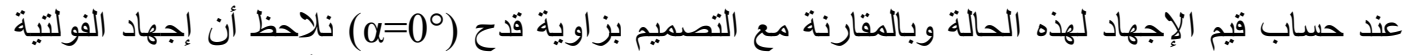

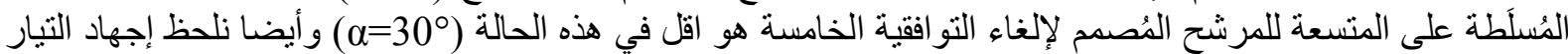

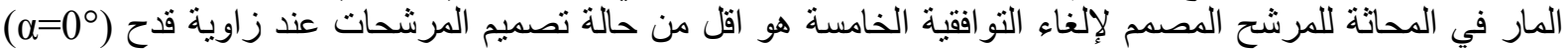

وكما موضح في الأشكال (21) و لمح (22) و (23). 

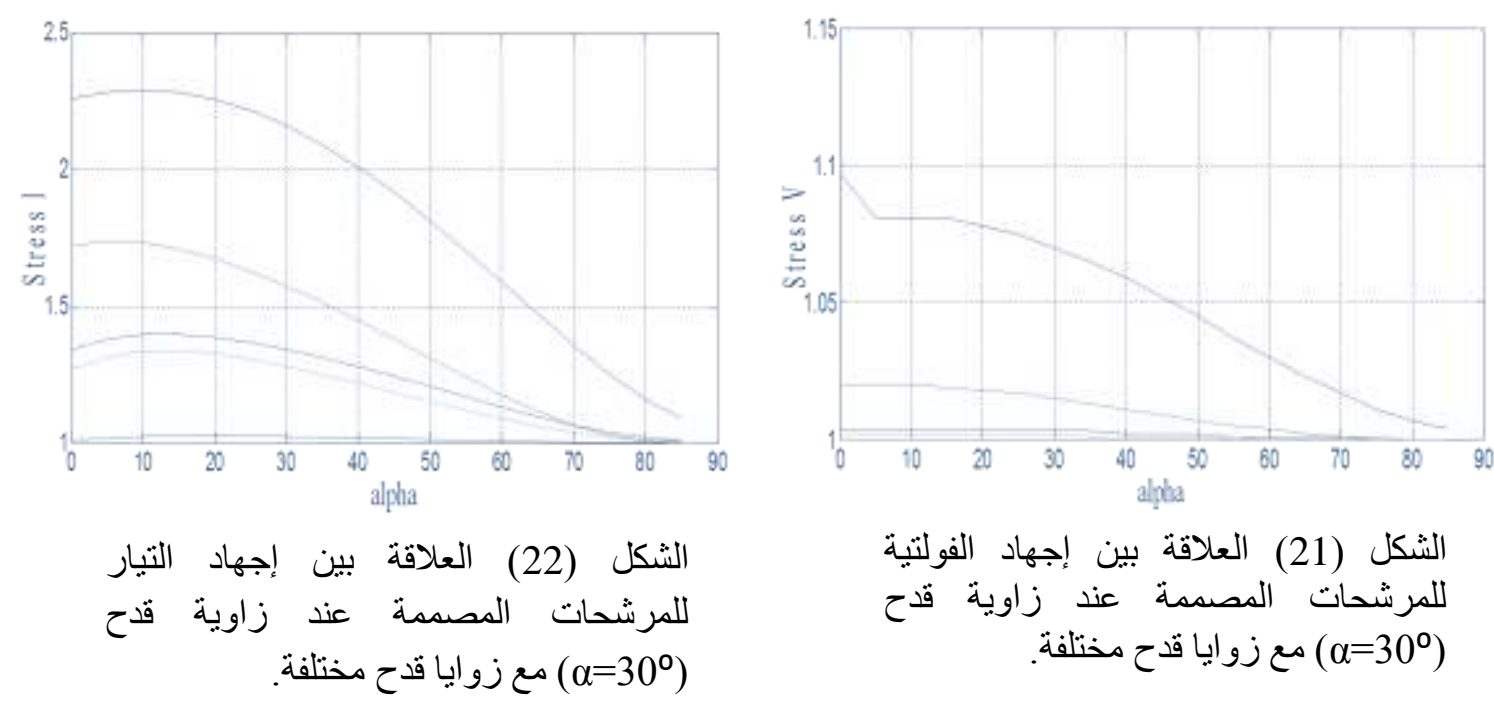

الشكل (21) العلاقة بين إجهاد الفولتية

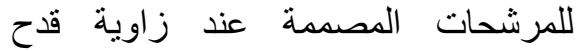
(

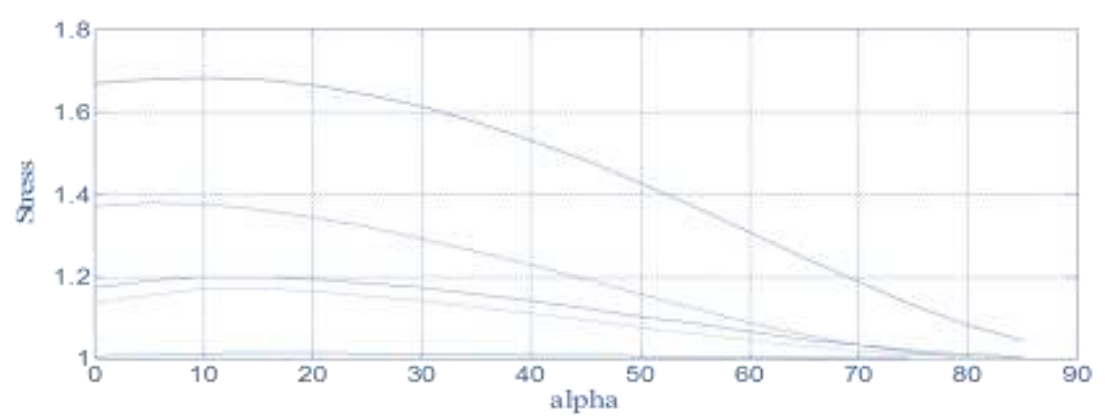

الشكل (22) العلاقة بين الإجهاد الكلي للمرشحات المصممة عند زاوية قدح (م=30ª ) مع زوايا قدح مختلفة. تبين من تغيير التصميم لعدة زوايا قدح ما يأتي:

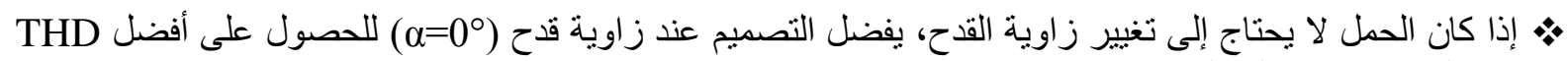

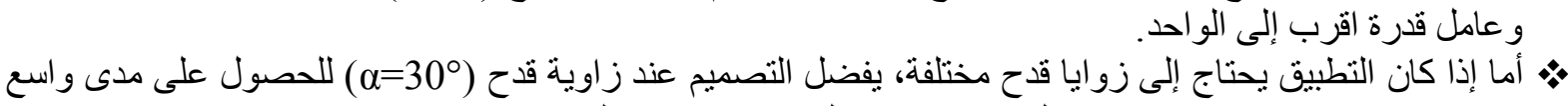
من تغيير ه بحيث إن THD تكون اقل من 5\% و و عامل قدرة قريبا من الواحد.

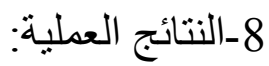

تم إجراء الاختبار العملي باستخدام بورد الثايرستور المختبري والمبينة خصائصه في الملحق (A)، استخدم المقوم ليغذي حملاً عالي الحثية.

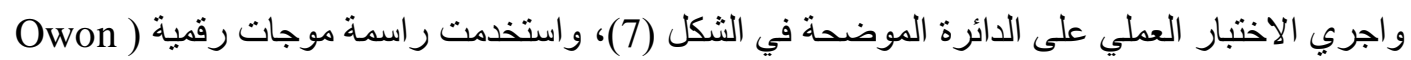

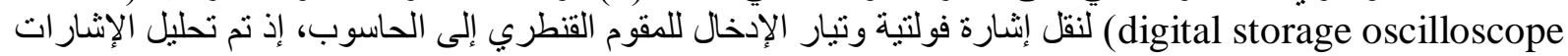

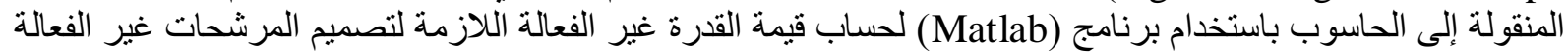
المطلوبة لإلغاء التوافقيات الظاهرة في موجة تيار الإخخال وتعويض القدرة غير الفعالة لتعديل عامل القدرة. 
وتم أيضا استخدام جهاز (3-PHASE POWER QUALITY (3945-B Power Pad)) لقياس قيمة

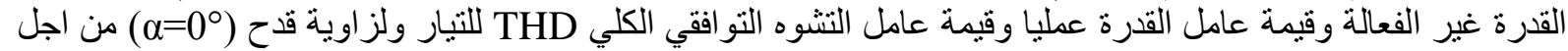

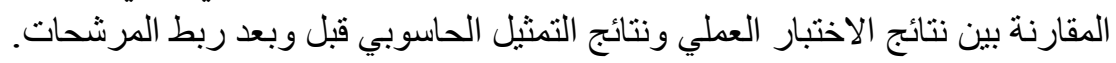

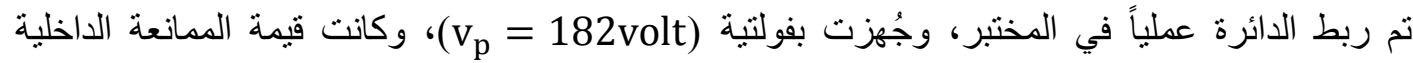

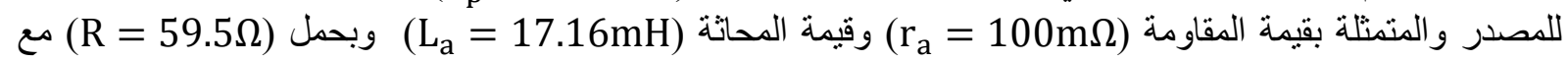

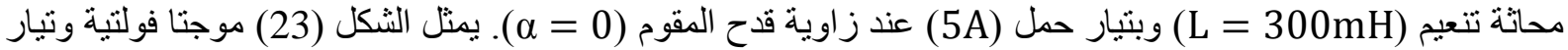
الإدخال للمقوم القنطري.

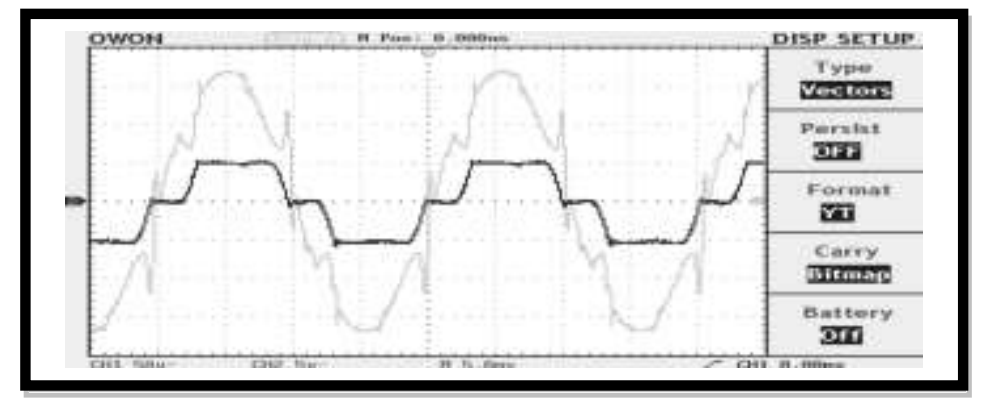

الثكل (23): فولتية وتيار الإدخال للمقوم القنطري ثلاثي الطور عمليا عند زاوية قدح (م=0).

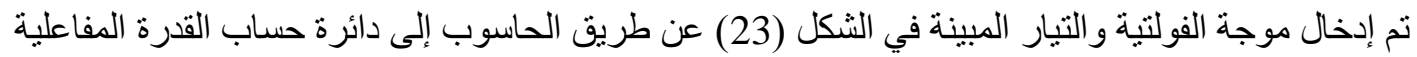

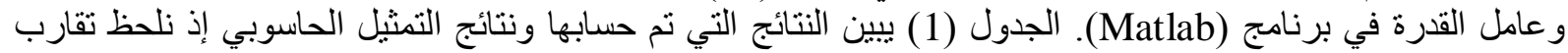
نتائج التمثيل الحاسوبي مع النتائج العملية بنسبة كبيرة:

الجدول (1) النتائج العملية ونتائج التمثيل الحاسوبي لقيم القدرة الظاهرية والحقيقية و غير الفعالة و عامل القدرة عند زاوية

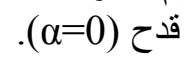

\begin{tabular}{|c|c|c|}
\hline حاسوبي & عملي & المتغيرات \\
\hline 477.8 & 525.1 & القدرة الظاهرية (VA) \\
\hline 456.1 & 498.8 & القدرة الحقققية (W) \\
\hline 142.3 & 164.1 & القدرة غير الفعالة (VAR) \\
\hline $0.9546 \mathrm{Lag}$ & $0.9499 \mathrm{Lag}$ & عامل القدرة \\
\hline
\end{tabular}

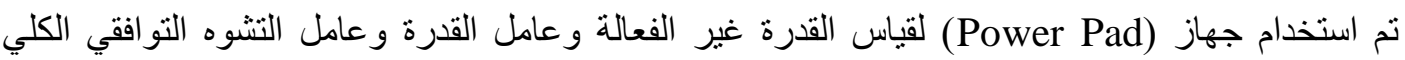

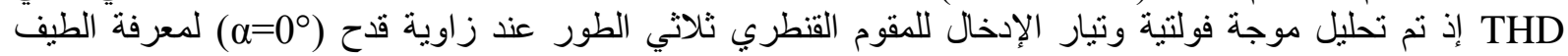

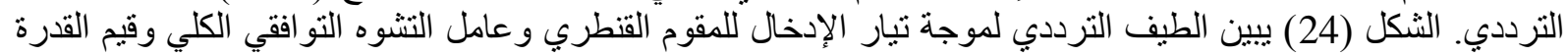
غير الفعالة و عامل القدرة.

تم ربط المرشحات غير الفعالة المُصممة مع دائرة المقوم القنطري ثلاثي الطور المحكوم عملياً. في الخطوة

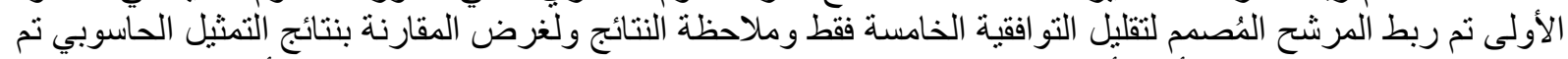

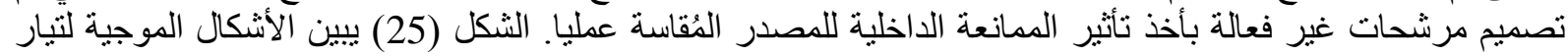

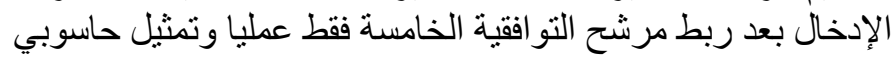


زينل: تحليل وتصميم المرشحات غير الفعالة لتقليل توافقيات تيار الخط في المقومات المحكومة
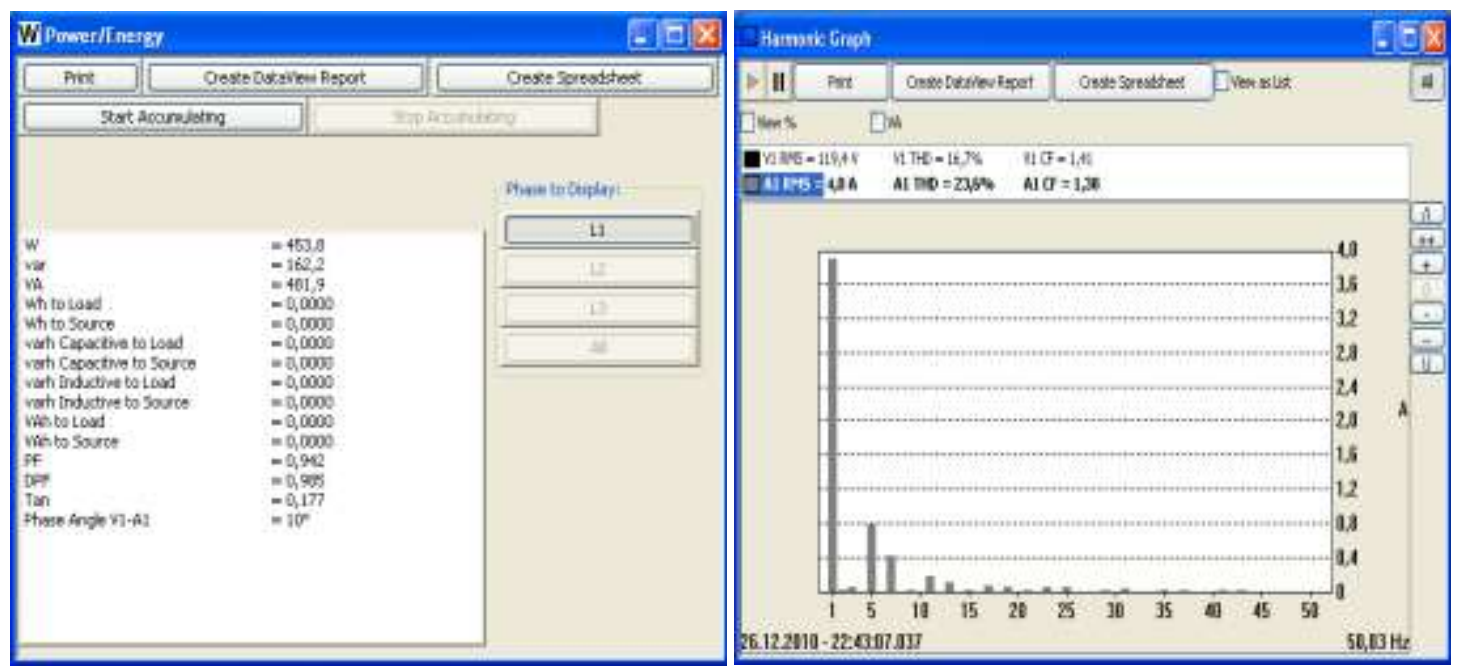

الثكل (24) النتائج العملية من جهاز Power Pad للتو افقيات الظاهرة، عامل التشوه التو افقي الكلي،القدرة

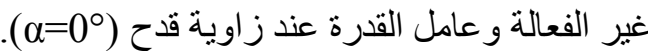

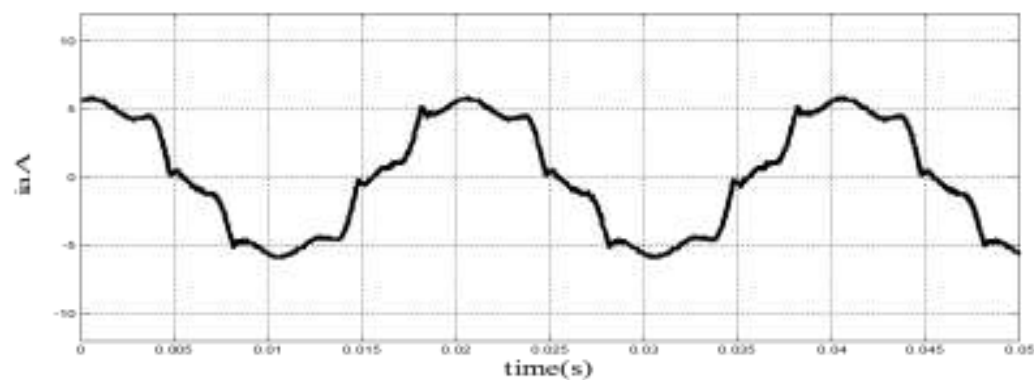

الثكل (25a) موجة تبار الإدخال (عملياً) عند ربط مرشح التو افقية الخامسة فقط.

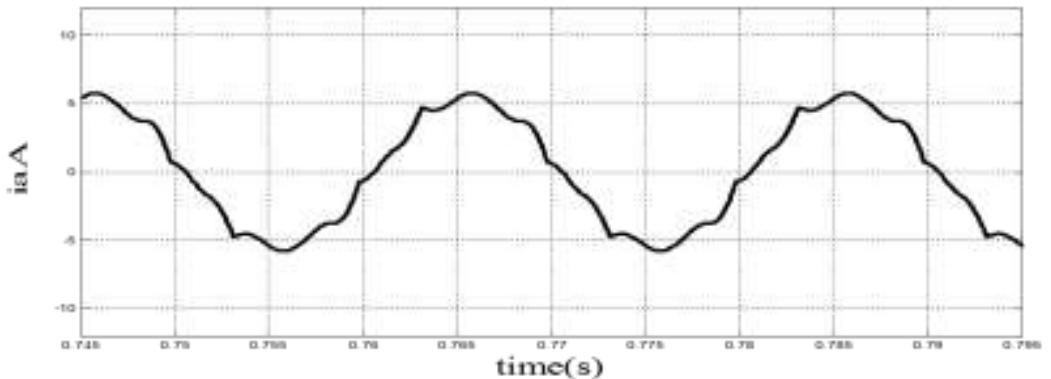

الثكل (25b) موجة تيار الإدخال عند ربط مرشح التوافقية الخامسة فقط باستخدام التمثيل الحاسوبي.

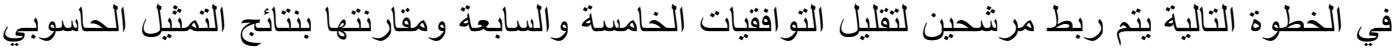

لتقليل التو افقيات نفسها. الثكل (26) يبين شكل موجة تيار الإدخال العملية والتمثيل الحاسوبي لموجة تئيل التيار الإدخال.

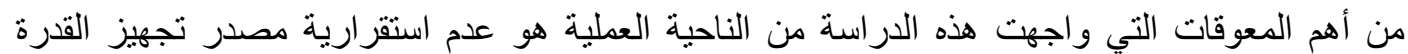

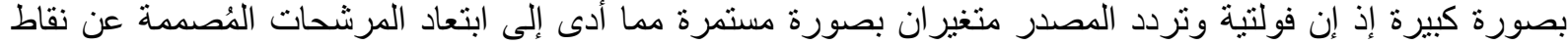

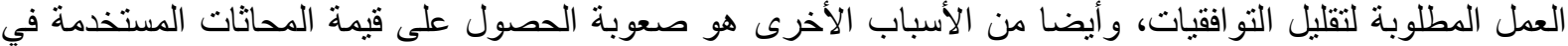
تصميم المرشحات. 


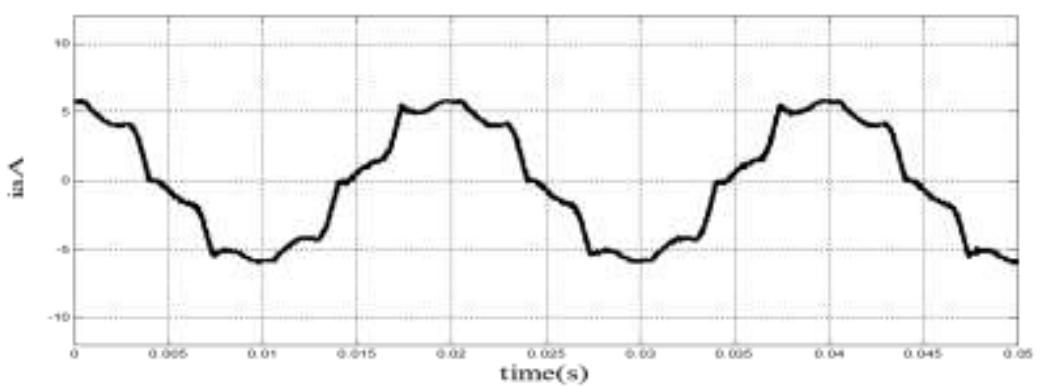

الثكل (26a) موجة تيار الإدخال (عملياً) عند ربط مرشحات التو افقية الخامسة و السابعة فقط.

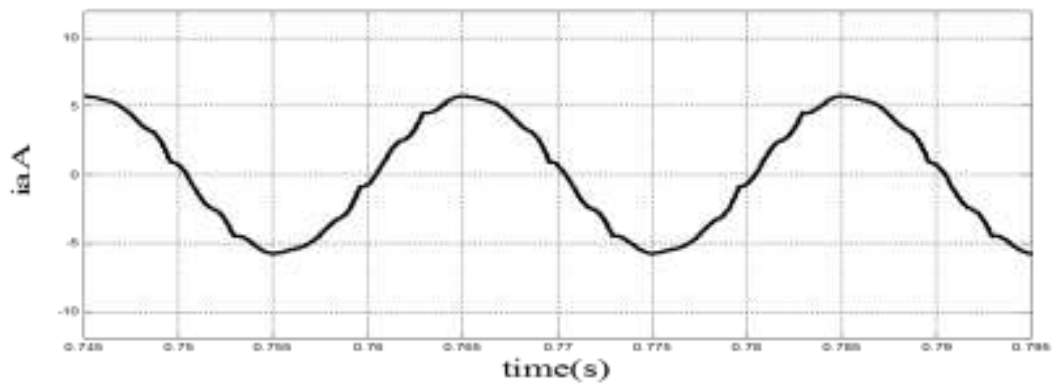

الثكل (26b) موجة تيار الإدخال عند ربط مرشحات التو افقية الخامسة والسابعة فقط باستخدام التمثيل الحاسوبي.

تم في هذا البحث استخدام طريقة ربط المرشحات غير الفعالة وهي من الطرائق الثائعة المستخدمة لتقليل التو افقيات، ويمكن أستخدامها في الأظمة الكهربائية عند مقنتات عالية ومنوسطة ورواطئة

وبالاعتماد على نتائج التحليل الرياضي والتمثيل الحاسوبي والنتائج العملية نم التوصل إلى الاستتناجات

1. إذا كانت زاوية القدح للمقوم متغيرة يفضل تصميم المرشحات عند معدل زوايا القدح للحصول على أفضل نسبة

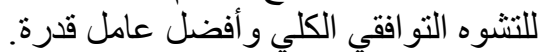

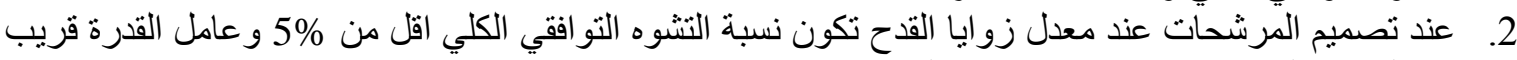

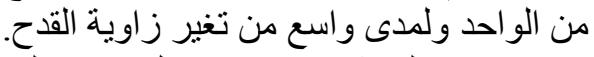

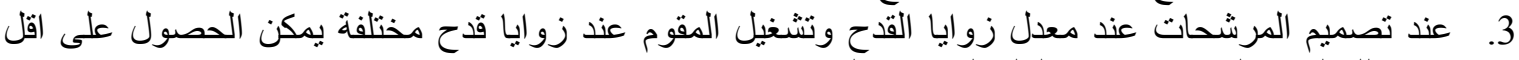

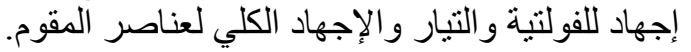

4. من الاستنتاجات المهمة هو انه يمكن تعميم طريقة التصميم المتبعة في هذا البحث لتشمل إي نوع من أنواع الأحمال غير الخطية.

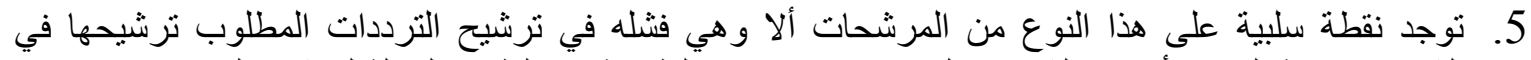

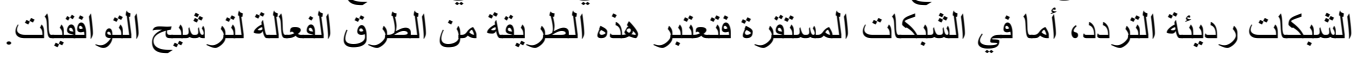

[1] Alexandre B. Nassif, and WilsunXu, "Passive Harmonic Filters for Medium-Voltage Industrial Systems: Practical Considerations and Topology Analysis", Power Symposium, Las Cruces, NM, Issue Date: Sep. 30-Oct.2 2007, IEEE. 
[2] Marwan Hazim Shehab Ahmed, "Current Harmonic Reduction of a Three-phase Controlled Converter By Using Two Anti-parallel Thyristors for Injection Current Adjustment", M. Sc. Thesis, University of Mosul, 2009. (in Arabic).

[3] Alexandre B. Nassif, WilsunXu, and WalmirFreitas, "An Investigation on the Selection of Filter Topologies for Passive Filter Applications”, IEEE VOL. 24, NO. 3, july, 2009.

[4] Gary W. Chang, Hung-Lu Wang, and Shou-Yung Chu, "A Probabilistic Approach for Optimal Passive Harmonic Filter Planning”, IEEE TRANSACTIONS ON POWER DELIVERY, VOL. 22, NO. 3, JULY 2007

[5] Muhammad H. Rashid, "Power Electronics: Circuits, Devices and Applications ", Third Edition, Pearson Prentice Hall, U.S.A, 2004.

[6] Three phase harmonic filters, Blocks (SimPowerSystems), MATLAB, v7.8.0 (R2009a).

[7] W. SHEPHERD and P.ZAND,"ENERGY FLOW AND POWER FACTOR IN NONSINUSOIDAL CIRCUITS", First published, Cambridge University Press, 1979.

[8] IEEE Standard 1459-2000, "IEEE Trial-Use Standard Definitions for the Measurement of Electric Power Quantities Under Sinusoidal, Nonsinusoidal, Balanced, or Unbalanced Conditions", 2000, IEEE.

تم اجراء البحث في كلية ألهندة = جامعة ألموصل 